\title{
Review Article \\ Investigation on Cardiovascular Risk Prediction Using Physiological Parameters
}

\author{
Wan-Hua Lin,, Heye Zhang, ${ }^{1,2}$ and Yuan-Ting Zhang ${ }^{2,3}$ \\ ${ }^{1}$ SIAT-Institute of Biomedical and Health Engineering, Chinese Academy of Sciences, Shenzhen 518055, China \\ ${ }^{2}$ The CAS Laboratory for Health Informatics, Shenzhen Institutes of Advanced Technology, Shenzhen 518055, China \\ ${ }^{3}$ Department of Electronic Engineering, Joint Research Centre for Biomedical Engineering, The Chinese University of Hong Kong, \\ Hong Kong
}

Correspondence should be addressed to Yuan-Ting Zhang; ytzhang@ee.cuhk.edu.hk

Received 14 July 2013; Accepted 23 September 2013

Academic Editor: Huafeng Liu

Copyright (c) 2013 Wan-Hua Lin et al. This is an open access article distributed under the Creative Commons Attribution License, which permits unrestricted use, distribution, and reproduction in any medium, provided the original work is properly cited.

Cardiovascular disease (CVD) is the leading cause of death worldwide. Early prediction of CVD is urgently important for timely prevention and treatment. Incorporation or modification of new risk factors that have an additional independent prognostic value of existing prediction models is widely used for improving the performance of the prediction models. This paper is to investigate the physiological parameters that are used as risk factors for the prediction of cardiovascular events, as well as summarizing the current status on the medical devices for physiological tests and discuss the potential implications for promoting CVD prevention and treatment in the future. The results show that measures extracted from blood pressure, electrocardiogram, arterial stiffness, ankle-brachial blood pressure index (ABI), and blood glucose carry valuable information for the prediction of both long-term and near-term cardiovascular risk. However, the predictive values should be further validated by more comprehensive measures. Meanwhile, advancing unobtrusive technologies and wireless communication technologies allow on-site detection of the physiological information remotely in an out-of-hospital setting in real-time. In addition with computer modeling technologies and information fusion. It may allow for personalized, quantitative, and real-time assessment of sudden CVD events.

\section{Introduction}

Cardiovascular disease (CVD) remains the world's top killer for death at this moment. As reported by World Health Organization [1], CVD will continue to dominate mortality trends in the coming decades. Moreover, it is always associated with substantial socioeconomic burden. Therefore, a considerable demand to improve cardiovascular health is greatly desired.

CVDs are chronic diseases that occur by long-term cumulative effects of risk factors. Besides, a large number of people die from acute cardiovascular events without prior symptoms [2]. And about two-thirds of deaths caused by CVD occur in out-of-hospital conditions [3]. It is therefore important to develop effective risk prediction approaches for screening individuals who are at high risk of developing CVD for timely prevention and treatment at an early stage before obvious symptoms happen.
In the past decades, several prediction models have been proposed to estimate a 10 -year risk of developing CVD. The models are expressed as multivariate regression equations using risk factors as variables. The most influential model is the Framingham Risk Score (FRS), which predicts coronary heart disease (CHD) using traditional risk factors as follows: age, diabetes, smoking, systolic blood pressure (SBP), treatment for hypertension, total cholesterol, and high-density lipoprotein (HDL) cholesterol [4]. Other similar risk-scoring algorithms, such as ATP-III [5], SCORE [6], PROCAM [7], QRICK [8], Reynolds Risk Score [9, 10], and MUCA [11], are accomplished through the incorporation of factors into the FRS or recalibration of the Framingham functions to the local subjects. These prediction models have become primary tools in the prevention of CVD in clinical practice. Based on these models, individuals classified in low risk stratum, intermediate stratum, and high risk stratum 
are recommended for lifestyle modification, further risk stratification or drug therapy, and more intensive preventive interventions, respectively [12].

However, they still have several known limitations. An example is that a considerable number of CVD events still occur in those asymptomatic patients who are classified into intermediate risk stratum [13]. Another example is that if subjects classified in the Framingham low-risk stratum are excluded from further screening, about a quarter of men and two-thirds of women with substantial atherosclerosis will be missed, where atherosclerosis is the main cause of CVD [14]. Therefore, in addition to traditional prediction approaches, further efforts should be made to develop novel strategies for accurately screening CVD.

Incorporation or modification of the risk factor that has an independent prognostic value of current prediction models would be a good choice for improving the performance of the prediction models. Some studies have reported the role of imaging [15], genetic test [16], and biomarker assay [17] in improving early CVD prediction. However, until now, there is not a study systematically reporting the role of physiological parameters for CVD prediction. Physiological parameters of the heart and arteries can be measured from the body surface by noninvasive tests and can be used for identifying multiphysics mechanisms of the cardiovascular system. Specifically, blood pressure (BP) reflects the hemodynamics inside the arteries. It is well known that high $\mathrm{BP}$ is a major cause of the development of atherosclerosis, an artery clogging and hardening process that results in heart attacks or strokes [18]. Electrocardiogram (ECG) measures the electrophysiology of the heart. Abnormalities on ECG can be used for screening vulnerable myocardium, which may lead to acute myocardial infarction [19]. Arterial stiffness measured by aortic pulse wave velocity (PWV) or pulse wave analysis reflects the blood fluid flow in the arteries and the hardening degree of the artery wall [20], where arterial hardening is a consequence of arteriosclerosis. Ankle-brachial blood pressure index (ABI), which is defined as the ratio of systolic pressure at the ankle to that in the arm, can be used for evaluating structural and functional changes in the blood vessel and has been used for measuring peripheral vascular disease. Blood glucose carries the biochemical information of the blood. Elevated plasma glucose may cause several conditions that relate to the development of cardiovascular complications [21]. Moreover, increased hemodynamics of blood flow and mechanical shear stress of the coronary wall, which are reflected in the increases in BP, heart rate, and PWV, in combination with the increases in blood viscosity, are responsible for triggering plaque rupture and consequence progression of CVD [19, 22], where, plaque rupture accounts for around $70 \%$ of acute cardiac deaths [19].

Except for established physiological risk factors (clinical SBP and diabetes) adopted in the traditional prediction models, more studies find that emerging physiological parameters extracted from ambulatory BP, stress BP, ECG, arterial stiffness, $\mathrm{ABI}$, and milder glucose abnormalities are also related to the occurrence of CVD. For examples, the Ohasama study shows that the heart rate variability (HRV) and blood pressure variability (BPV) captured by ambulatory blood pressure monitoring (ABPM) should be regarded as independent risk factors for the prediction of CVD death in general individuals [23]. The Dublin study suggests that the nighttime $\mathrm{BP}$ can be more effective in the prediction of CVD mortality than clinical BP [24]. The Framingham study shows that exercise diastolic blood pressure (DBP) during stage 2 of the Bruce protocol and recovery predict incident CVD when adjusted for resting BP [25]. A metaanalysis of 17 longitudinal studies suggests that the risk of subjects with high aortic PWV is almost twice compared with those with lower aortic PWV [26]. The Strong Heart Study shows that low ABI $(\leq 0.90)$ and high $\mathrm{ABI}(>1.40)$ significantly improve the CVD mortality risk [27]. The Framingham Offspring Study indicates that milder glucose abnormalities such as impaired fasting glucose (IFG) or impaired glucose tolerance (IGT) are also independent risk factors for predicting CVD though the predictive values are small, and the risk increases mostly in those with combined IFG and IGT. Medical statistics studies also prove that early morning $\mathrm{BP}$ and heart rate surge $[22,28,29]$, elevated $\mathrm{BP}$ in winter [29], exercise-induced ECG arrhythmias in athletes [30], and electrophysiological abnormalities in obstructive sleep apnea [31] are related to an increased incident of acute CVD events, such as myocardial infarction (MI) and stroke. In addition, noninvasive monitoring of these physiological parameters are convenience, cost-effective, and with low side effects. Therefore, it would be another good choice for improving CVD prediction by the use of physiological parameters that have been proved to be with independent prognostic values.

The objective of this paper is to review current evidences regarding these physiological parameters for CVD prediction, as well as to summarize the current status of the medical devices that used for monitoring these parameters and discuss the potential implications for promoting CVD prevention and treatment in the future.

\section{Assessing the Predictive Ability of Risk Factors}

Cohort studies in which populations are followed up over time and outcomes are determined prospectively are widely used for measuring the prognostic value of a risk marker for disease prediction and treatment [32]. Generally, the number of the population enlisted should be large and the followup should be conducted for years to get large numbers of outcome events for significant statistical analysis. In these studies, risk is assessed with a survival curve or by reporting the proportion of outcome events over a given period [32]. The statistical association between a risk marker and the outcome can then be tested using the Cox proportional hazards model, linear regression model, logistic regression model, or a parametric survival model and are assessed using metrics such as hazard ratio (HR), odds ratio (OR), or relative risk ( $R R$, equal to relative hazard), along with confidence interval (CI) and $P$ value $[20,32]$. The $H R$ refers to the ratio of the hazard rates corresponding to two levels of a variable. For instance, subjects with treatment or a particular exposure may suffer an outcome two times than the control 
subjects, giving a $\mathrm{HR}$ of 2 . The odds ratio refers to the odds that an outcome will occur with a particular exposure, compared to that without the exposure. Relative risk refers to the ratio of the probability of developing a disease in the exposed group versus the control group. Therefore, HR, OR, or RR of 1 means that the exposure or treatment does not influence the risk of developing the outcome, HR, OR, or $\mathrm{RR}>1$ means exposure or treatment associated with higher risk of developing the outcome, while $\mathrm{HR}, \mathrm{OR}$, or $\mathrm{RR}<1$ means exposure or treatment associated with lower risk of developing the outcome. Consequently, exposures with HR, OR, or RR far from 1 may be considered as risk factors for predicting disease outcome (e.g. CVD). For a risk factor to be considered with independent and incremental predictive value, the metrics should be calculated after adjustment for established risk factors.

More analysis including discrimination, calibration, and reclassification are also recommended by the American Heart Association for assessing the performance of risk prediction models with the inclusion of new markers $[12,32]$. Discrimination represents the ability of a prediction model to discriminate cases from no cases [12]. It is quantified using $C$ statistic or $\mathrm{C}$ index, which is equal to the area under the receiver operating characteristic curve (AUC) $[12,20]$. A test with $\mathrm{C}$ statistic of 0.5 means no discrimination, while 1.0 means a prefect test. Calibration measures the capability of predicting accurately the proportion of individuals in a group who will develop disease events. Metric of Hosmer-Lemeshow $\chi^{2}$ test is usually used for describing the calibration of a risk prediction model [12]. Reclassification refers to the ability whether the individuals reclassified into other risk stratums will be more accurate [20]. Net reclassification improvement and integrative discrimination index are two metrics for quantitatively estimating the reclassification $[12,32]$.

Apart from the statistical measures described above, a new risk marker should also have a positive effect on clinical decisions and eventually on clinical outcomes [32]. Ultimately, the test for capturing the novel risk factor should be cost-effective, so it can be used for screening large scale individuals [32].

\section{Initial Studies on Early CVD Prediction Using Physiological Parameters}

3.1. Blood Pressure (BP). BP is a consistent risk factor for the development of atherosclerosis [18]. Specially, high BP increases the workload of the heart and injures the endothelium and the delicate lining of the artery walls. Injured endothelium will induce the deposition of cholesterol and cells in the artery wall and eventually lead to the formation of atherosclerosis plaques. Plaques can suddenly rupture, and cause blood clots that can block blood flow travelling to vital organs, such as the heart or the brain. Then ischemic heart disease or cerebrovascular accident will occur. Moreover, stress-induced hemodynamic and hemostatic changes will increase the likelihood of plaque rupture and thrombosis.

Continuous or category variables derived from resting BP, $\mathrm{ABPM}$, and stress BP tests are used for cardiovascular risk

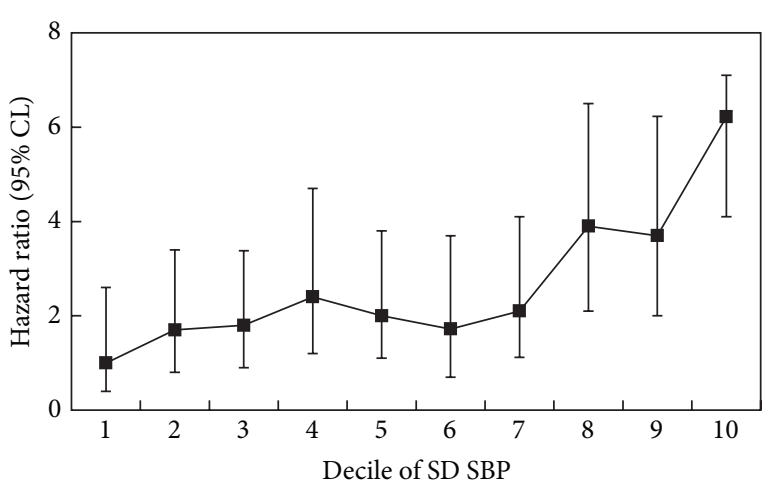

FIGURE 1: Hazard ratios for risk of stroke by deciles of visit-to-visit variability (SD) SBP over seven visit measurements (the interval between visits was 4 months), with the first decile as the control category. Analyses were performed in patients excluding those with a past history of stroke (1324 patients were eligible). Reproduced from [34].

prediction. Table 1 shows some of the representative cohort studies reporting the independent predictive value of BP.

3.1.1. Resting Blood Pressure. Accumulating traditional large scale cohort studies prove that high brachial artery BP at baseline is the most prevalent treatable vascular risk factor $[8,33,34,38]$. A meta-analysis of one million adults shows that cardiovascular risk starts to increase as SBP rises from $115 \mathrm{mmHg}$ or DBP rises from $75 \mathrm{mmHg}$ to higher values [38]. The Japan Arteriosclerosis Longitudinal Study (JALS) group compares $4 \mathrm{BP}$ indexes (DBP, SBP, pulse pressure [PP], and mean blood pressure $[\mathrm{MBP}]$ ) and finds that SBP and MBP are the strongest predictors for the long-term incidence of stroke and myocardial infarction (MI), while PP is the weakest predictor of the four BP indexes [33].

In a recent persuasive study, variability in SBP and maximum SBP reached among repeated clinic visits over months are also demonstrated to be strong predictors of stroke, independent of mean SBP. As shown in Figure 1 and Table 1, the HR of the top-decile of SD SBP over seven visits for stroke prediction is 6.22 , while the HR of the top-decile of maximum SBP reached for stroke prediction is 15.01, after adjustment for mean SBP (the first decile is the reference category) [34].

Diagnosis and treatment of hypertension are commonly recommended for the prevention of CVD events. Antihypertensive agents that can reduce BPV and MBP both will control the risk of stroke more effectively than agents who reduce MBP only $[39,40]$. A meta-analysis finds that effects of drugs on interindividual variation in SBP account for more of the effects of treatment on stroke risk than do effects on mean SBP [41]. Thus, BPV is suggested to be taken into account to the current hypertension guidelines [42].

3.1.2. Ambulatory Blood Pressure. Blood pressures vary greatly according to the daily activities and may reflect the cerebrum central autonomic control. As reported by many 


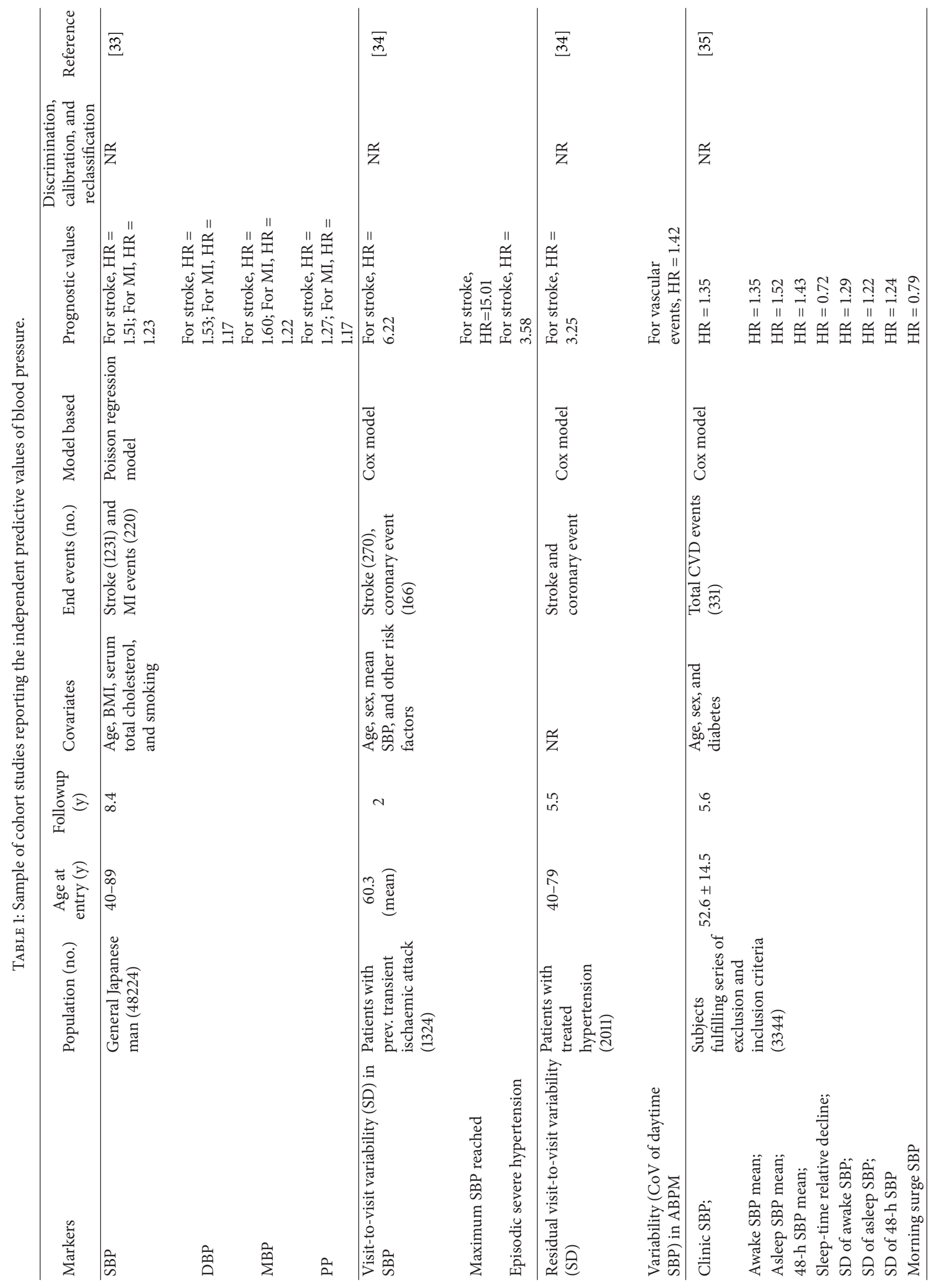




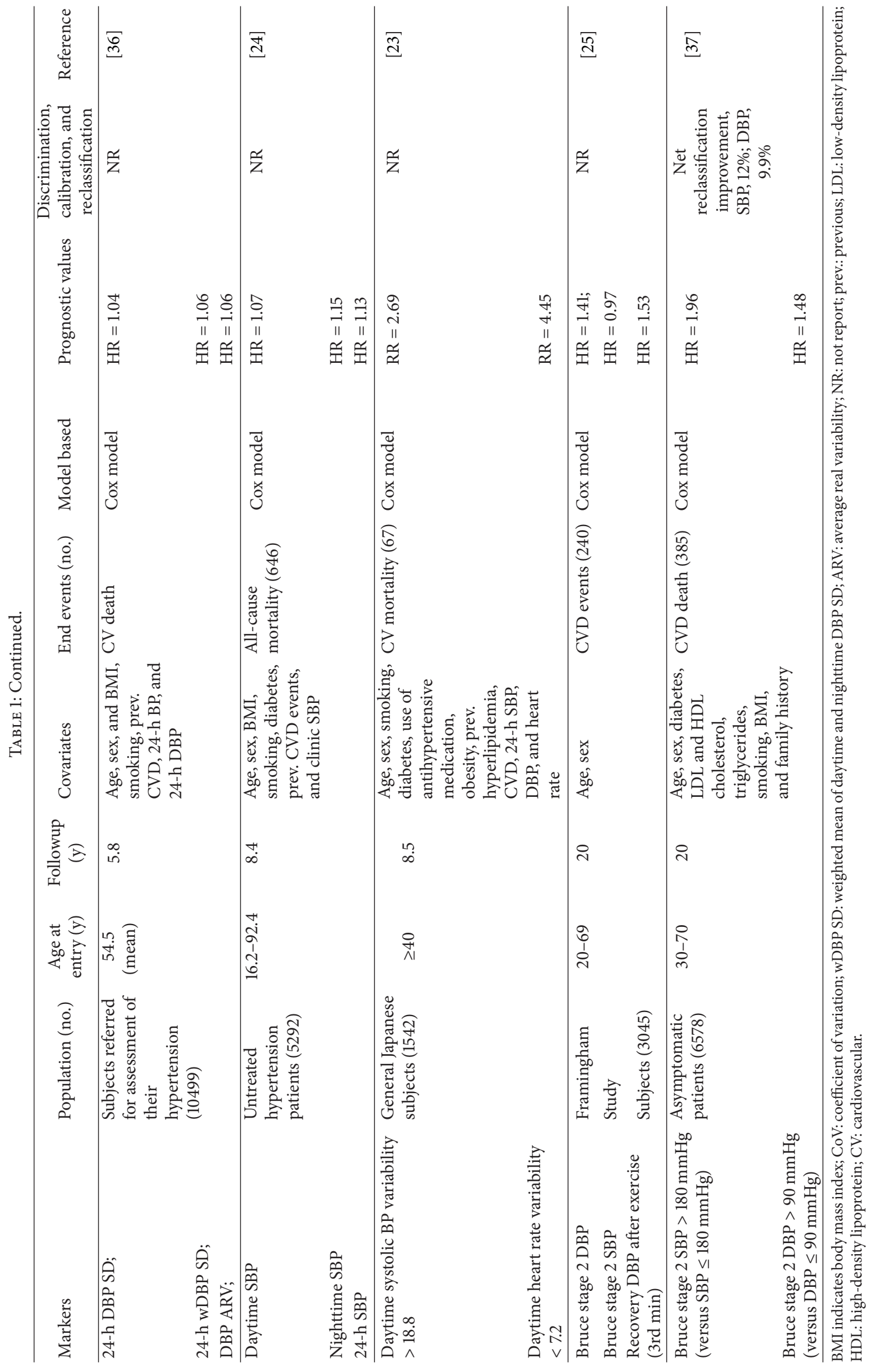




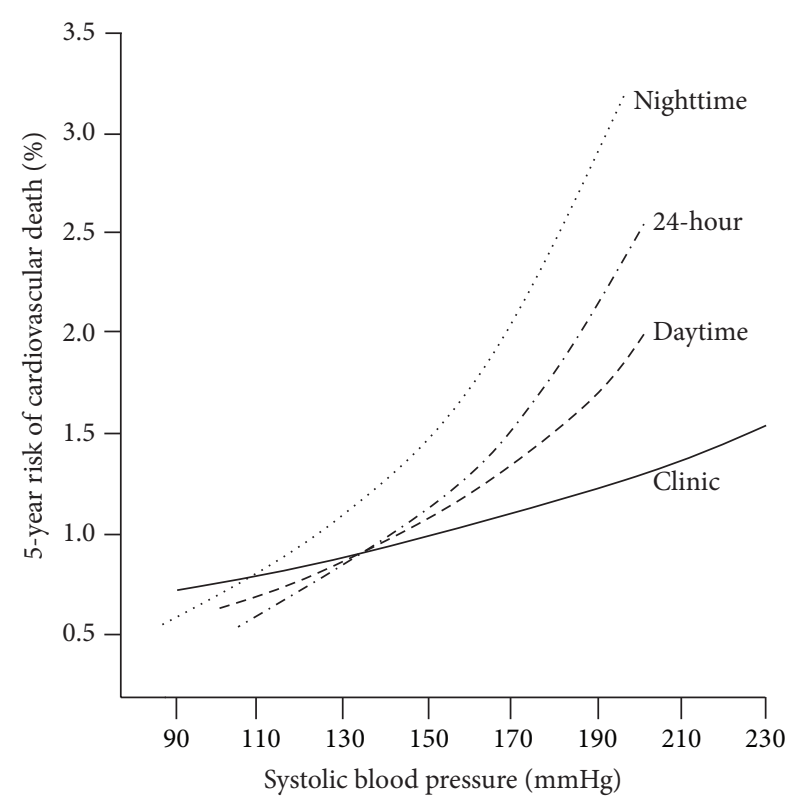

FIgURE 2: Adjusted 5-year risk of cardiovascular mortality versus systolic blood pressure captured by ambulatory blood pressure monitoring in different periods of the day. Reproduced from [24].

researchers, ABPM can be used for monitoring the variability pattern of BP, which can provide additional important information missed under office BP monitoring or common home monitoring, and is superior to clinic BP measurement in predicting mortality [24].

Different indexes including daytime BP mean, nighttime $\mathrm{BP}$ mean, $24 \mathrm{~h} \mathrm{BP}$ mean, and night-to-day BP ratio in ABPM are indicated to consistently predict all CVD events. Figure 2 depicts an adjusted 5-year risk of cardiovascular death versus SBP captured by ABPM in the Dublin study [24]. It indicates that elevated nighttime BP mean is a better predictor of cardiovascular risk than 24 hour BP mean, daytime BP mean, or clinic BP, which is just the same as other common studies showed [43-46]. Another role of ABPM for the prediction of CVD events is that it could be used for evaluating the BPV during different periods of time. Short-term variability is estimated as the variation of reading-to-reading at baseline ABPM. The Ohasama study shows that the RR for daytime ambulatory systolic BPV $>18.8$ is $2.69(P=0.02)$, with the BPV of 11.5-13.9 as the reference category, suggesting a strong predictive value for cardiovascular mortality [23]. Other cohort studies also prove that an increase in readingto-reading BPV is only slightly associated with an increase in subsequent CVD events/complications (HRs are slightly larger than 1) $[35,36,47]$. Conversely, some studies find that the association loses in the presence of other well-known risk factors. The elusive results are in part because of the different sample and different BPV index adopted.

Other evidences indicate that an abnormal pattern of cyclic variation of BP (circadian or seasonal) is correlated well with an increased cardiovascular risk [29]. For example, excessive increase of BP just after rising in the morning, blunt, or nondipping of nocturnal BP (night-to-day BP ratio $\geq 1$, sleep hypertension) is correlated with increased cardiovascular risk $[28,48,49]$. Such correlation could also be found in people with obstructive sleep apnea (OSA), whose $\mathrm{BP}$ rises at night while the risk of sudden cardiac death increases during sleep [31]. Besides, elevation of seasonal BP variation will increase cardiovascular risk. A study shows that the $\mathrm{BP}$ rises in the winter, while the frequency of acute MI increases by $53 \%$ in the winter [29].

Further study evaluates the different effects of taking antihypertension medications in different periods of time with the use of ABPM [50]. The results show that bedtime dosing would be better than morning do.se in improving $\mathrm{BP}$ control including lowering the nocturnal BP, $24 \mathrm{~h} \mathrm{BP}$ mean, or the morning BP surge. Intervention study also demonstrates that the progressive decrease in asleep BP mean captured by ABPM can efficiently reduce cardiovascular risk [35].

3.1.3. Stress Blood Pressure. Abnormal exercise BP response is demonstrated to be associated with an imbalance of autonomic nervous regulation, a future hypertension, and a future hypertensive left ventricular hypertrophy [51-53], suggesting a link to a high risk for the development of CVD. Though exaggerated exercise BP response and attenuated BP recovery are demonstrated to show prognostic information in identifying cardiovascular risk, even in normotensive individuals $[25,37,54]$. The results of the prognostic value are still controversial $[25,37]$. That depends in part on the stage when $\mathrm{BP}$ is measured in the exercise and different exercise BP indexes adopted [37].

Two important studies (as shown in Table 1) report that submaximal BP during exercise is greater than maximal BP in predicting the risk of CVD death $[25,37]$. One study, the Framingham study, shows that DBP during stage 2 of the Bruce protocol and recovery rather than SBP predict incident CVD when adjusted for resting BP [25]. The other study shows that Bruce stage $2 \mathrm{BP}$ (submaximal exercise $\mathrm{BP}$ ) $>180 / 90 \mathrm{~mm}$ Hg identifies normotensive individuals at higher risk of CVD death, independent of rest BP [37].

3.2. Electrocardiograph (ECG). Abnormalities on ECG reflect the electrical instability of the myocardium; therefore ECG can be used for screening vulnerable myocardium, which may lead to acute myocardial infarction [19]. Compared to conventional risk factors corresponding to long-term risk, ECG abnormalities are better for predicting shortterm risk [55]. Quantitative measures assessed from resting ECG, ambulatory ECG, and stress ECG have been reported for predicting subsequent CVD events and mortality. At the present epidemiological studies, ECG abnormalities are widely evaluated with the use of Minnesota Code (MC) or Novacode (NC) [56].

3.2.1. Resting ECG. Abnormal ECGs relating to heart rate, conduction, left ventricular mass, or repolarization are shown to link to cardiovascular risk. The prognostic measures used include increased heart rate, left ventricular hypertrophy (LVH) [57], ST segment depression [58], negative $\mathrm{T}$ wave [58], pathological Q wave [56], left bundle branch blocks 


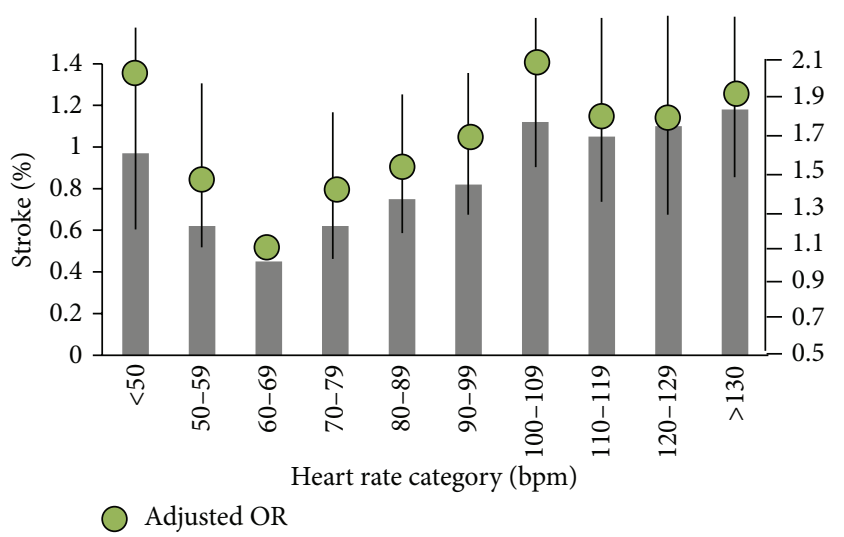

FIGURE 3: The risk of stroke versus heart rate groups. The heart rate group of $60-69 \mathrm{bpm}$ is used as the reference category. Reproduced from [65].

(LBBB), arrhythmias (e.g., atrial fibrillation), QRS duration [59], and QT interval prolongation [60]. Some studies have tried to investigate pooled categories by combining some of the abnormalities above for improving the prognostic value. The pool categories used include major and minor abnormalities [61], ECG strain pattern [62, 63], and ischemic ECG findings (Minnesota codes I3, IV1-3, V1-3, or VII1) [64].

Large prospective cohort studies including the CRUSADE [65] and INVEST [66] show that the relationship between resting heart rate and adverse cardiovascular outcomes follows a "J-shaped" curve. Figure 3 depicts the relationship between the risk of stroke and heart rate groups in 135164 patients with acute coronary syndromes [65]. The risk of stroke increases with heart rate below or above the lowest point of 60-69 bpm. Other studies also show that increased resting heart rate can be used as a strong, graded, and independent risk factor for predicting incident CVD, especially for the sudden death from MI [67, 68]. Further cohort trials including the BEAUTIFUL and SHIFT studies prove that heart rate reduction benefiting from betablockers and other heart-rate lowering drugs is associated with a reduction of mortality in patients with coronary artery disease [69-71]. The possible pathophysiological mechanisms for the effects of elevated rest heart rate include the direct detriment on the progression of coronary atherosclerosis, on the occurrence of MI and ventricular arrhythmias, and on the left ventricular function [69]. A faster heart rate will necessarily impose more shear stress than a slow one [67] thus increases the likelihood of disruption of preexisting atherosclerotic plaque [72], which may lead to the occurrence of acute coronary artery disease.

ECG LVH may imply severe hypertension, which is related to elevated cardiovascular risk [73]. Numerous prospective cohort studies, including the Framingham study and the LIFE study, prove the value of LVH diagnosed by ECG criteria for predicting cardiovascular morbidity and mortality in hypertensive patients $[57,74,75]$. The predictive value is particularly great when repolarization abnormalities (i.e., ST depression and negative T wave) are present $[62,63]$. Antihypertensive treatment that can induce the regression of ECG
LVH will reduce the risk of CVD events, independent of how much the BP is lowered [57, 74]. However, ECG is insensitive when used alone for screening LVH; the criteria for diagnosis of LVH are different [57]. Magnetic resonance imaging (MRI) is used as a standard for left ventricular mass measurement [76], while other techniques like echocardiography can also be used for the diagnosis of LVH [57].

ST segment depression and negative $\mathrm{T}$ waves, reflecting repolarization abnormalities, are markers of ischemic diseases. ST depression, isolated $\mathrm{T}$ wave abnormalities, and combined ST-T change are indicated to be independent predictors for cardiovascular death in substantial epidemiological data $[56,58,77,78]$. Joint occurrence of ST-T change in combination with ECG LVH is the ECG abnormality with the greatest prognostic information for the future cardiac incidents [62].

Q-wave abnormality indicates myocardial tissue damage. It is usually used as a marker for identifying unrecognized or "silent" cardiac disease (e.g., unrecognized MI) [55]. Evidences from clinical studies indicate that both Q-wave alone and unrecognized MI diagnosed by ECG criteria based on Q-wave show the value for predicting the risk of mortality, heart failure, or stroke $[56,79,80]$.

Composite variables such as major and minor abnormalities are used for the prediction of CVD events and mortality in asymptomatic persons [61]. The Women's Health Initiative clinical trial including 14749 postmenopausal asymptomatic women shows that the addition of ECG findings to the FRS increased AUC from 0.69 to 0.74 , which indicates an improvement of the risk discrimination [61].

3.2.2. Ambulatory ECG. The prognostic values of ambulatory heart rate parameters including increased daytime "nighttime" $24 \mathrm{~h}$ heart rate, increased night-to-day heart rate ratio (heart rate nondipping), and decreased heart rate variability (HRV) are recently studied. A cohort study with 6928 subjects and with a 9.6-year followup shows that nighttime heart rate predicts cardiovascular mortality $(\mathrm{HR}=1.15)$ night-to-day heart rate ratio predicts cardiac $(\mathrm{HR}=1.23)$ and coronary $(\mathrm{HR}$ $=1.17$ ) outcomes, while $24 \mathrm{~h}$ and daytime heart rate provide little prediction value for the identification of cardiovascular risk (HRs are slightly greater or less than 1.0) [73]. Heart rate variability (HRV) is affected by both vagal and sympathetic modulation of the sinus node. Diminished HRV reflects a decreased vagal activity, which increases the risk of death [81]. In a clinical study, reduced HRV measured in standard deviation of normal-to-normal intervals (SDNN) or lowfrequency power (LF) is shown to be independent predictors of mortality after myocardial infarction or heart failure [82]. The Ohasama study shows that the RR for daytime HRV $<$ 7.2 is $4.45(P=0.003)$, with the HRV $>14.0$ as the reference category, suggesting a strong predictive value for identifying cardiovascular mortality [23]. Another study shows that the impaired heart rate deceleration capacity is a powerful predictor of mortality in postinfarction cohort, with a better AUC (0.74) than SDNN (0.64) [81]. However, conventional HRV indices lose predictive power in patients with MI, who have treatment with betablocks and revascularization [82]. In 
summary, the prediction value of ambulatory heart rate now remains low and somewhat controversial.

3.2.3. Stress ECG. The stress ECG measures, including STsegment deviation, failure heart rate increased, low heart rate recovery, and exercise-induced abnormalities (e.g., ventricular ectopy), show independent predictive value for identifying cardiovascular risk, even in patients with clinically normal resting electrocardiograms [20,83-85].

Descending ST-segment during exercise is used for assessment of ischemia [86]. Exercise-induced ST-segment depression $\geqslant 1.0 \mathrm{~mm}$ of horizontal or down-sloping STsegment depression at $80 \mathrm{~ms}$ after the J point is considered to be abnormal and is shown to be associated with sudden cardiac death and all-cause mortality $[83,87]$. However, most of the adjusted HRs are only a litter more than 1 . The isolated ST-segmentation loses the prognostic value in asymptomatic women [84].

Heart rate responses to exercise reflect the function of autonomic nervous system and offer predictive value for major CVD and total death [20]. Failure of the heart rate to rise appropriately during exercise (termed chronotropic incompetence) reflects a "blunted" sympathetic reaction [20, 86]. Abnormal chronotropic index $\leqslant 0.80$, not achieving target heart rate, and exercise-induced heart rate increased $<89 \mathrm{bpm}$ are shown to be independently predictive of MI, CHD death, and all-cause mortality in large cohort studies $[84,86,88]$. By contrast, reduced fall of the heart rate appropriately after exercise (termed reduced heart rate recovery) reflects an increased sympathetic activity or lack of vagal activity [20]. Reduced heart rate recovery with different cutoff values (e.g., $<12,18,22$, or $25 \mathrm{bpm}$ after $1 \mathrm{~min},<22$ or $42 \mathrm{bpm}$ after $2 \mathrm{~min}$, and $<50$ after $3 \mathrm{~min}$ ) is proved to provide additional, independent prognostic information of mortality $[84,88,89]$. A study shows that chronotropic incompetence (with HR of 2.8) is a stronger predictor of cardiovascular death than heart rate recovery (with $\mathrm{HR}$ of 2.0) [90]. In summary, heart rate recovery is limited by the variable recovery protocols and variable criteria for abnormality. It needs a further refinement before being used in making clinical decisions.

Quantitative measures of exercise-induced abnormalities, including higher heart rate, more leftward QRS axis, longer QT interval, and frequent ventricular ectopy in recovery, are shown to provide modest additional prognostic value [83].

Another non-ECG measure in the stress test, reduced exercise capacity, measured in metabolic equivalents (METs) or exercise duration, is proved to be one of the strongest predictors of cardiac and all-cause mortality among both healthy persons and those with CVD $[91,92]$.

Composite variables by synthesizing the measures above are used for predicting cardiovascular risk. For example, a composite ECG score by the combination of heart rate, conduction, left ventricular mass, and repolarization information in exercise ECG is adopted for improving the discrimination ( $\mathrm{C}$ index increases 0.04 ) and the reclassification of risk of mortality [83]. Duke treadmill score (DTS) by the combination of exercise capacity, ST-segment deviation, and exercise-induced angina pectoris is used for the posttest of risk stratification [93]. Another nomogram-illustrated model, which takes account of additional demographics (age, sex), simple risk factors (smoking, hypertension, and diabetes), and exercise test predictors (heart rate recovery and stress-related ventricular ectopy), is demonstrated to be better than DTS at risk discrimination ( $C$ index, 0.83 versus $0.73)[20,89]$. More details can be seen in Table 2.

3.3. Arterial Stiffness. Arterial stiffness is a consequence of arteriosclerosis, which integrates the effects of genetic background and long-term cumulative damage of cardiovascular risk factors in the arteries $[20,26,94]$. On the other hand, the increased arterial stiffness will lead to increased pulsatile component of BP, which is a valuable factor in modulating atherosclerosis progression and atherosclerotic plaque instability and thereby leading to acute coronary syndromes and other vascular complications [94]. Commonly applied methods for measuring arterial stiffness in epidemiological studies conclude aortic pulse wave velocity (PWV) and pulse wave analysis [95].

3.3.1. Aortic PWV. Aortic PWV is defined as the speed of travel of the aortic pulse wave, which directly influences the regional blood flow field around the plaque. It is calculated as the distance between two selected sites divided by pulse transit time [26]. The velocity of pulse wave propagation turns to be fast when the arteries become stiff. Thus, PWV reflects the arterial stiffness [20]. Measuring aortic PWV from the carotid to the femoral artery (cfPWV) was regarded as the clinical gold standard for assessing aortic stiffness [26]. However, the clinical application of cfPWV is limited by complicated measurement and the need to expose the privacy region in patients. Brachial-ankle pulse wave velocity (baPWV) is shown to be significantly correlated to cfPWV and is widely used in Asia for its convenience measurement [96].

Studies including a meta-analysis of 17 longitudinal studies analyze the increased aortic PWV as a strong independent predictor of the risk of CVD events $[26,97]$. The risk of subjects with high aortic PWV is almost twice compared with those with lower aortic PWV (the cut-off values for dividing the high versus low stiffness groups are different from 8.2 to $17.7 \mathrm{~m} / \mathrm{s}$ in different studies) [26]. It is increasingly used in clinical practice [98]. When PWV is added to standard risk factor models, the discrimination slope increases from 7.8 to 8.5 in Framingham study [99], while in Rotterdam study, the area under ROC curve improves from 0.70 to 0.72 [100].

3.3.2. Pulse Wave Analysis. As shown in Figure 4, central BP waveform is a sum of a forward traveling wave, generated by ventricular ejection, and a reflected wave coming back from the periphery [94]. Augmentation pressure $(\Delta P)$ is calculated as the SBP (the peak of the observed wave) minus the peak of the forward waveform. Thus, augmentation pressure represents the additional SBP due to the wave reflection [94]. Increased PWV due to increased arterial stiffness would lead to the increased overlap between forward and backward 


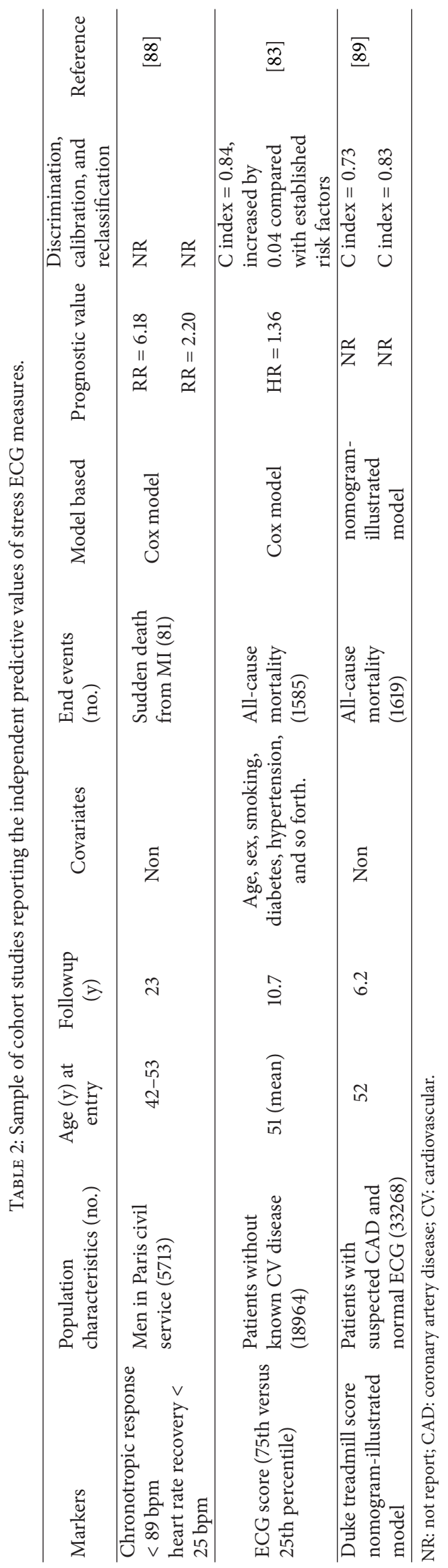




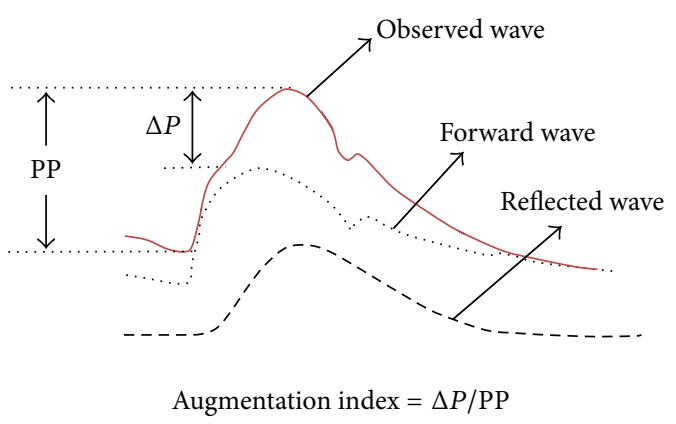

FIGURE 4: A central blood pressure waveform which contains a forward and a backward (reflected) components. PP indicates pulse pressure. Reproduced from $[94,95]$.

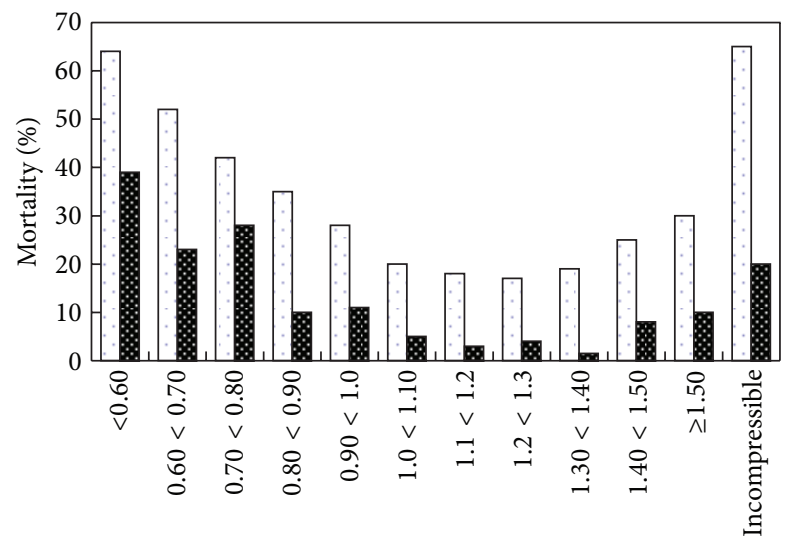

$$
\begin{aligned}
& \square \text { All-cause mortality } \\
& \text { ¿ CVD mortality }
\end{aligned}
$$

FIGURE 5: All-cause and CVD mortality according to ankle-brachial index (ABI) groups. Reproduced from [27].

wave, which would enhance the augmentation pressure and subsequently central SBP and pulse pressure [94]. Central $\mathrm{BP}$, pulse pressure, and aortic augmentation index (AIx) therefore indirectly reflect the arterial stiffness. The pulse pressure is calculated as SBP minus DBP, while the AIx is expressed as $\triangle P$ to a proportion of the central pulse pressure, $\mathrm{PP}(\triangle P / \mathrm{PP})$, as shown in Figure $4[94,95]$.

There are researches demonstrating that central $\mathrm{BP}$ is superior to brachial BP and brachial PP in the prediction of CVD events in an unselected geriatric population and hypertensive patients [101-103]. The predictive power is stronger in the younger group than in the older group, since aging will lessen pulse pressure amplification [102]. Pulse pressure is reported to be a weak predictor [33]. In the geriatric population $\geq 65$ years, brachial PP loses its predictive power while central PP remains a valid predictor of CVD events [101]. AIx predicts adverse cardiovascular events in patients with established coronary artery disease [104], predicts CHD in men undergoing angiography [105], and predicts mortality in patients with end-stage renal failure [106]. However, it yields conflicting results in patients with systolic heart failure. In these kinds of people, patients with lower values of central PP or AIx have more advanced systolic dysfunction [107]. Besides, AIx is not a reliable measure of arterial stiffness in people with diabetes [108]. A recent study reports that reflected wave magnitude, but not AIx, predicts cardiovascular death independent of cfPWV [109]. Other measures including ambulatory arterial stiffness index (AASI) [110] and carotid pulse pressure (versus brachial pulse pressure) [101] are studied within general populations.

As described above, reflective pulse wave analysis and PWV are commonly used for measuring arterial stiffness. However, they are different in the following: (1) wave reflection analysis is sensitive to pulse wave velocity, the wave reflection site, the duration and pattern of ventricular ejection, changes in heart rate, and antihypertensive drugs, while PWV reflects the inherent stiffness of the arterial wall [95]; (2) AIx is considered to be a more sensitive marker in younger individuals, while aortic PWV is a better predictor in older individuals [111]; (3) aortic PWV may be more useful for measuring long-term changes in arterial stiffness, whereas wave reflection analysis reflects short-term changes, for example, in the condition of therapeutic interventions [95].

In therapeutic trials, destiffening strategies with the use of antihypertrophic drugs, which have the benefit of reducing wave reflections and subsequently lowering the central SBP and PP, show significant reduction of cardiovascular risk [94]. For example, diuretic and calcium antagonist which with the effect of lowering central SBP and PP is better than classic betablocker which reduces the peripheral SBP only in lowering cardiovascular risk [94]. A recent study indicates that vasodilatory antihypertensives have the effect of reducing the central BP independently of the peripheral BP [103].

3.4. Ankle-Brachial Index. Ankle-brachial blood pressure index (ABI) is defined as the ratio of systolic pressure at the ankle to that in the arm. It is another parameter for evaluating structural and functional change in the vascular and is used for measuring peripheral vascular disease. An abnormal low ABI $(\leqslant 0.90)$ indicates the presence of peripheral artery disease, which is defined as $>50 \%$ stenosis, while an abnormal high ABI (>1.40) indicates artery calcification. Mortality risk increases both at abnormally low or high ABI. Slightly abnormal values ( 0.91 to 1.10 ) also have a graded association with CVD risk $[20,112]$.

Numerous epidemiological studies prove that an abnormal $\mathrm{ABI}$ is associated with an increased cardiovascular risk $[20,113]$. Figure 5 shows an association between mortality and $\mathrm{ABI}$ groups in the Strong Heart study, which includes 4393 individuals aged $45-74$ and followup of $8.3 \pm 2.2$ years [27]. We can see that low ABI $(\leqslant 0.90)$ and high ABI $(>1.40)$ significantly improve the mortality risk. A metastudy by following up of 24955 men and 23339 women shows that, for a low $\mathrm{ABI}(\leqslant 0.9)$ compared with a normal ABI (1.11 to 1.40$)$, the HR for 10 -year cardiovascular mortality is 4.2 for men and 3.5 for women. When adjusted for FRS, the values are 2.9 and 3.0, respectively, indicating that, by adding the abnormal ABI as a risk factor, the risk prediction extends beyond that of the 


\begin{tabular}{|c|c|c|c|c|}
\hline$\stackrel{5.6}{\mid}$ & IFG & $\stackrel{7.0}{i}$ & Diabetes & FPG \\
\hline 7.8 & IGT & 11.0 & Diabetes & 2-h PG \\
\hline
\end{tabular}

FIGURE 6: Categories for prediabetes and diabetes mellitus FPG, fasting plasma glucose. $2 \mathrm{~h}$ PG, 2 hour plasma glucose in the oral glucose tolerance test. IFG: impaired fasting glucose. IGT: impaired glucose tolerance.

FRS [113]. The MESA study shows that the AUC improved by the addition of ABI to the FRS is 0.036 [114].

3.5. Blood Glucose. Elevated plasma glucose may cause several conditions that relate to the development of cardiovascular complications, such as thrombophilic condition, endothelial dysfunction, and enhanced platelet adhesion [21]. The relationship between glucose level and cardiovascular incident is graded and independent [115]. Cut-off values for defining glucose abnormalities are modified recently with regard to the risk of cardiovascular [116]. According to the latest 2012 American Diabetes Association (ADA) criteria, categories for glucose abnormalities classification are based on fasting plasma glucose (FPG) and $2 \mathrm{~h}$ plasma glucose $(2 \mathrm{~h}$ PG) in the oral glucose tolerance test, as shown in Figure 6 [116]. Individuals whose FPG levels are of $5.6 \mathrm{mmol} / \mathrm{L}$ to $7.0 \mathrm{mmol} / \mathrm{L}$ are thought to have impaired fasting glucose (IFG), while people with $2 \mathrm{~h}$ PG values of $7.8 \mathrm{mmol} / \mathrm{L}$ to $11.0 \mathrm{mmol} / \mathrm{L}$ are thought to have impaired glucose tolerance (IGT). And those with either FPG of $>7.0 \mathrm{mmol} / \mathrm{L}$ or $2 \mathrm{~h} \mathrm{PG}$ of $>11.0 \mathrm{mmol} / \mathrm{L}$ are thought to have diabetes.

Hyperglycemia for cardiovascular risk prediction is widely investigated in cohort studies. Diabetes is proven to be established factors in predicting CVD risk and is widely applied in clinical practice. Besides, cohort studies including the Framingham Offspring Study and a meta-analysis suggest that milder glucose abnormalities such as IFG or IGT are also independent risk factors for predicting CVD though the predictive values are small (HRs are slightly larger than (1)), and the risk increases mostly in those with combined IFG and IGT $[115,117,118]$. Some data show that $2 \mathrm{~h}$ PG is a better risk predictor than IFG [118].

\section{Initial Studies on Physiological Parameters for Near-Term CVD Prediction}

Researchers are trying to further identify the individuals who are at high risk of developing near-term CVD events and are in most urgent need of intervention [119]. To date, tools to predict near-term cardiovascular risk after acute coronary syndromes (ACS) are already available, such as the 7-point Thrombolysis in Myocardial Infarction (TIMI) risk score (for forecasting 30-day mortality) and the Global Registry of Acute Coronary Events (GRACE) risk score (for assessing the risk of six-month postdischarge death) [119]. However, there is not an algorithm that can be used for forecasting near-term risk in asymptomatic populations. With the addition of new sensitive risk factors that directly relate to the pathological process of CVD may promote the development of near-term prediction strategies.

58 international clinical experts from different groups have shown that vulnerable patients characterized as vulnerable plaques (prone to thrombotic complications and rapid progression), vulnerable blood (prone to thrombosis), and vulnerable myocardium (prone to fatal arrhythmia) are those people at high risk of developing acute cardiovascular events [2]. Some cardiovascular parameters captured by physiological tests have been proved to be directly related to the process of atherothrombotic plaque rupture, blood vulnerability, and myocardial susceptibility. As mentioned before, blood pressure, arterial stiffness, ABI, and blood glucose reflect the regional blood flow field conditions (blood pressure, blood velocity, and blood viscosity) of the blood vessels, which are responsible for triggering plaque rupture and consequence progression of CVD. ECG reflects the vulnerable property of the myocardium, whose abnormalities often lead to acute myocardial infarction. Therefore, physiological parameters are those sensitive risk factors that directly relate to the pathological process of CVD.

There are several prospective cohort studies showing the evidences of using physiological parameters as risk factors for predicting near-term risk of CVD events. The Cardiovascular Health study shows that diabetes, SBP, atrial fibrillation (AF), and ECG-defined LVH are associated with short-term risk of stroke (with followup of 3.31 years) in older adults [120]. $\mathrm{ABI}$ is shown to be highly associated with one-year risk of cardiovascular death in a cohort study with 6880 old patients (OR adjusted by age and sex was 3.7) [121]. Aortic augmentation pressure, a measure of arterial stiffness, is shown to be significantly predictive of adverse cardiovascular outcomes in 297 patients with coronary artery during 1.23.3 years of followup [104]. Increased arterial wave reflection, another measure of arterial stiffness, also proves to be highly associated with severe short-term CVD events in 262 patients undergoing percutaneous coronary intervention during 2year followup [122].

Therefore, in addition of emerging factors extracted from physiological signals may be benefit for the assessment of near-term CVD risk.

\section{Developments in the Medical Devices for Physiological Parameter Test}

In daily clinical practice, physiological parameters of the heart and arteries are measured from the body surface by noninvasive or mini-invasive tests. For instance, resting ECG is captured with the use of electrodes that adhere directly to the surface of the skin. Ambulatory ECG is collected with the use of a portable Holter [20]. Resting BP is examined by clinical examination or home visit using a mercury sphygmomanometer or a validated digital automatic BP monitor with placing a cuff on the brachial artery surface [40]. Ambulatory $\mathrm{BP}$ monitoring is performed using an ambulatory BP monitor with placing a cuff on the brachial artery surface [28]. PWV 


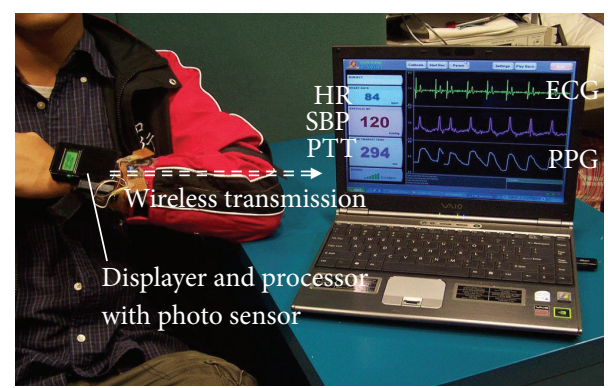

Figure 7: A health shirt designed in our research center for capturing multiparameters including ECG, PPG, and cuffless BP. Reproduced from [135].

is commonly collected using an applanation tonometry [123] but can also be measured by Doppler probes [109] or MRI [124]. Noninvasive arterial waveform measurement is generally obtained by placing an applanation tonometry on the peripheral artery surface (carotid or radial artery). For ABI monitoring, arm BP and ankle BP (posterior tibial artery) are commonly collected by Doppler. Blood glucose measurement is mini-invasive. Laboratory blood glucose value is collected using biochemical analyzer. In electrochemical meters, the concentration of glucose in the blood specimen is estimated by detecting the charge generated by the oxidation reaction using enzyme electrodes. When immediate blood glucose monitoring is performed out of the laboratory, blood sample is collected by piercing the skin (typically, on the finger) with a needle then applying the blood to a disposable glucose reagent strip. Compared to other modalities of tests for early CVD prediction, such as imaging [15], genetic test [16], and biomarker assay [17], noninvasive monitoring of physiological parameters have the advantages of ease of use, simple procedure, small cost, and low side effects.

In the past decades, novel unobtrusive monitoring methods have been invented to acquire physiological signals and parameters without disturbing the subject's daily life or even without awareness, such as ECG, heart rate, BP, and blood glucose. For ECG monitoring, noncontact sensors based on capacitively coupled principle and embedded in furniture, clothing, or wearable accessories provide an avenue for unobtrusive sensing of ECG [125]. The heart rate can be calculated indirectly from signals that can be detected unobtrusively, including ECG, photoplethysmography (PPG), and video images of a subject's face [126]. It can also be detected directly using unobtrusive sensors. For example, it can be detected remotely by microwave radar sensors based on the Doppler effect [127]. For BP monitoring, advanced technologies are focusing on developing methods that can be used for capturing BP continuously and noninvasively without using a cuff [125]. Radial pulse waveform acquired by arterial tonometry [128] and pulse transit time (PTT) measured from ECG and PPG signals $[129,130]$ provide two promising techniques for continuous and cuffless BP monitoring. Technologies advanced in blood glucose detection concentrate on developing needle-free, transcutaneous methods for noninvasive and continuous measurements. Potential technologies include impedance spectroscopy, reverse iontophoresis, enzyme-based direct electron, transfer electrophoresis, near infrared spectroscopy, and photoacoustic spectroscopy $[131,132]$. Some of the technologies have been integrated into wrist-worn devices, such as GlucoWatch biographer, for unobtrusive measurement [133]. In addition, there are no direct evidences showing the measurement of arterial stiffness and ABI using unobtrusive devices. Radial pulse waveform acquired by arterial tonometry suggests the potential possibility of measuring arterial stiffness through reflective pulse wave analysis. A study also introduces a novel potential method for assessing arterial stiffness based on finger height and PTT [134]. And the emergence of cuffless BP measurement may also make assessing ABI with unobtrusive devices become possible.

The captured physiological health information from unobtrusive instruments can then be transmitted to a remote clinical center using wireless communication technology. In this way, the patient's CVD status can be remotely monitored in an out-of-hospital setting in real-time. Figure 7 provides an example of a health shirt designed in our research center for unobtrusively multiparameters monitoring including ECG, PPG, and cuffless BP [135]. In this system, the garment is made from e-textiles for ECG monitoring, and PPG detector is embedded in the "watch-like" device. BP is estimated based on PTT which is measured from ECG and PPG signals. And all the health information is transmitted to a distanced control center by wireless transmission.

\section{Computer Modeling for the Management of CVD}

CVD is an extremely heterogeneous disease, with multiple forms of phenotypes and disease mechanisms. Increased technologies have provided the risk markers of the CVD and the information of cardiovascular system in multimodalities and multiscales. High-resolution imaging can supply the information of structure, component, and metabolism. Genetic test and biomarker assay provide the information at cellular, molecular, and protein levels. Physiological test reflects the hemodynamics and electrophysiology of the cardiovascular system. However, by means of current measurements of cardiac function are no longer specific enough to identify exactly the type of CVD a patient may suffer. Computer modeling supplies an opportunity for the fusion of the multiscale information through an unified platform for the understanding of CVD progress comprehensively and precisely and even for predicting the CVDs. It has been shown recently that computational models integrating multiscale health information can provide a quantitative assessment of the physiological and pathological activities of organism from simulation environment. For example, the Virtual Physiological Rat (VRP) Project develops computer models that integrate disparate data of genomic, anatomic, physiological, and so forth to explain and predict specific functions and diseases [136]. A multiscale cardiac functional modeling platform developed by the Heart Physiome Project can be used for demonstrating the mechanisms that underlie cardiac arrhythmia and fibrillation $[137,138]$. The euHeart 


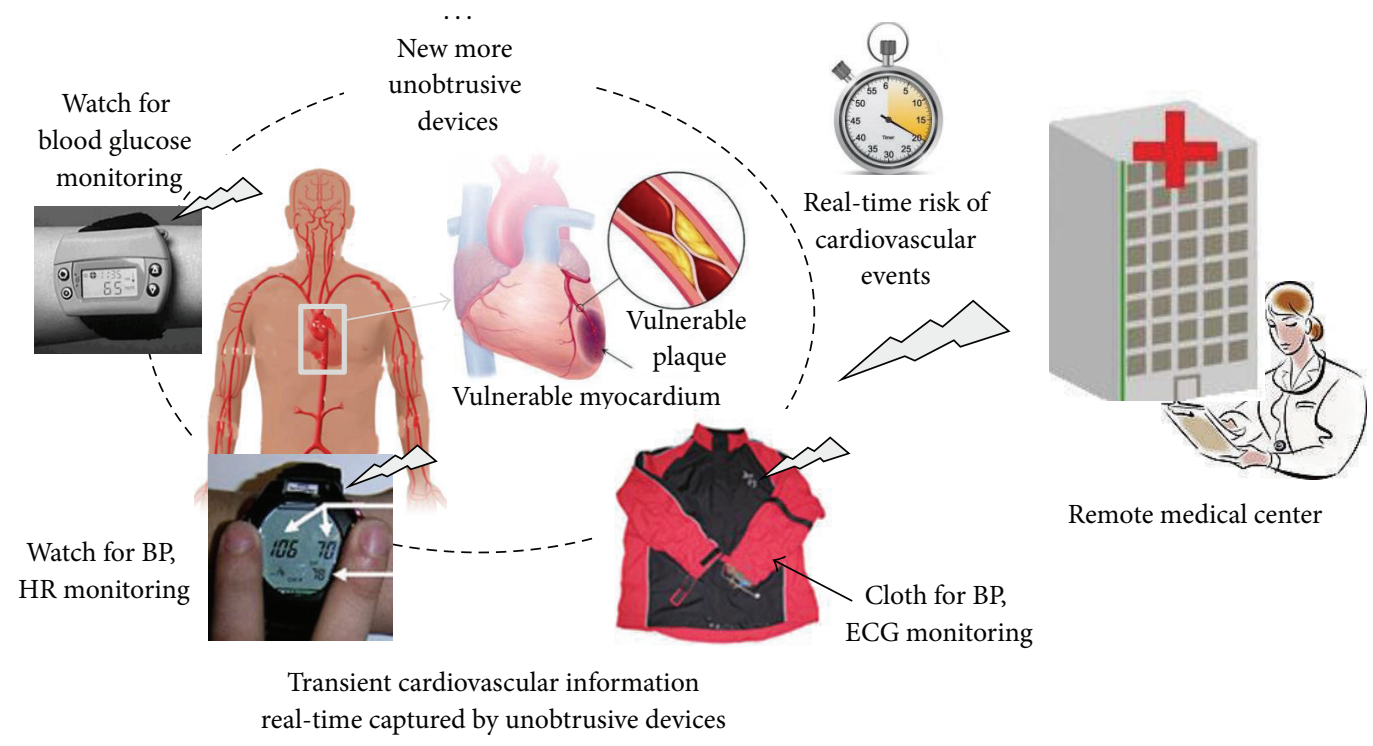

FIGURE 8: A blue print of real-time prediction of sudden cardiovascular events by physiological test using unobtrusive medical devices. The devices in the print are from $[125,133]$. BP: blood pressure; HR: heart rate.

Project develops patient-specific cardiovascular modeling frameworks for personalized and integrated cardiac care [139]. Wang et al. develops an integrated model based on tagged MRI data for better understanding of the underlying passive ventricular mechanics that adapt to pathophysiological changes [140].

\section{Discussion and Conclusion}

After review, established and potential physiological risk factors used for the early CVD prediction are systematically summarized in Table 3. Predictive power, significance, and limitations are also presented for each of the predictors in the table. Currently, most of the studies assess the prognostic values of physiological risk factors by reporting adjusted $\mathrm{HR}, \mathrm{OR}$, or RR with $\mathrm{CIs}$ and $P$ values. The results show that measures extracted from blood pressure, ECG, arterial stiffness, ABI, and blood glucose are statistically associated with adverse CVD events. However, only a small number of studies further report other more rigorous metrics such as calibration, discrimination, and reclassification for assessing the performance of a risk prediction model with the inclusion of the new markers. There are also limited studies reporting the effects on CVD events reduction by doing management of these factors. Thus, more studies are needed to provide more comprehensive measures before these risk factors to be considered useful for providing incremental predictive information over a standard risk assessment profile. It is noteworthy that the new cardiovascular risk factors should be validated before they are adopted in standard clinical care according to the following phases [32]: initial proof of the notion, prospective verification in independent individuals, documentation of additional information when added to established risk factors, evaluation of effects on patient treatment and outcomes, and cost-effectiveness, which are proposed by the American Heart Association.

Emerging factors captured by means of continuous or long-term monitoring, such as visit-to-visit blood pressure variability, elevated nighttime blood pressure, elevated nighttime heart rate, morning surge of blood pressure and heart rate, chronotropic incompetence, and reduced heart rate recovery, are proved to be with powerful prediction. This indicates the prospective applications of unobtrusive medical devices in the field of CVD prediction and management. First, with the use of unobtrusive methods for the continuous, real-time, and long-term collection of the physiological signals and parameters, critical risk markers can probably be extracted for predicting plaque rupture and acute CVD events. Second, continuous and long-term collection of the fluctuating health information before the near events will help unravel the dynamic mechanism of the CVD progression. Third, unobtrusive devices are suitable for on-site detection in out-of-hospital settings in real-time, which will allow taking preemptive treatments in response to the acute CVD events. However, as mentioned before, BP, ECG, and blood glucose now can be monitored unobtrusively, and arterial stiffness and ABI have also shown potential to be monitored in an unobtrusive way. Besides, techniques such as motion artifact elimination are needed to be overcome to acquire high quality signals for reaching unobtrusive monitoring in real life.

Current CVD prediction models are based on statistical analysis of populations and can hardly provide a basis for personalized prognosis because of the individual difference. Advancing technologies, such as high resolution imaging [15], genetic test [16], biomarker assay [17], and physiological monitoring, now can provide multiscale health information of the heart, spinning from gene, protein, cell, issue, organ, to the system levels. Computational models 


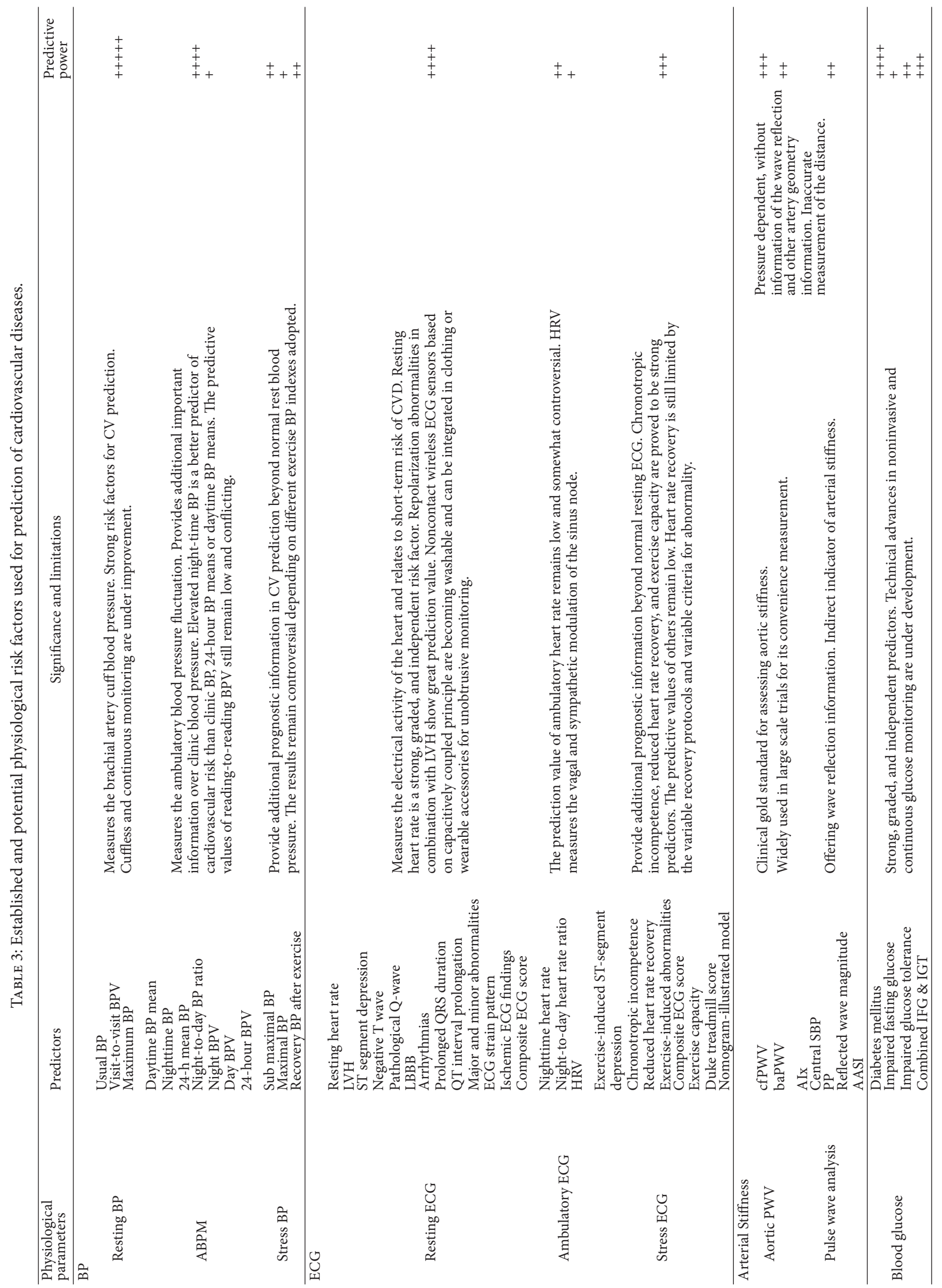




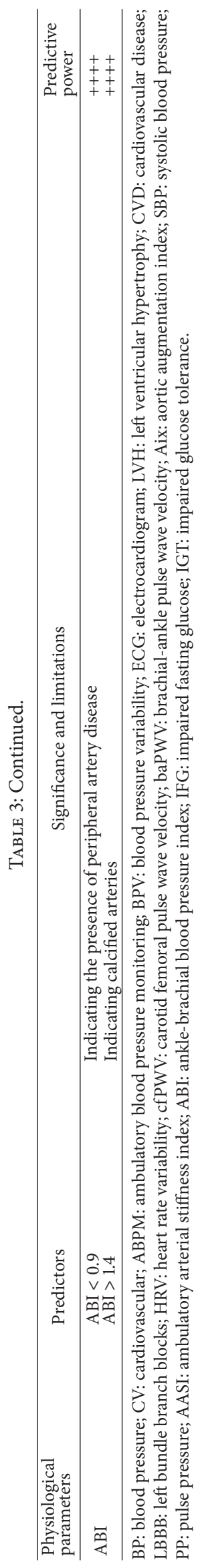


that integrate the multiscale health information provide a pathway for a patient-specific quantitative assessment of the physiological and pathological activities of the cardiovascular system from a simulation environment [141]. Therefore, a multiscale patient-specific model based on computer model technology and information fusion theory is prospected to be constructed for allowing the prediction of the cardiac mechanisms from observing signals. In this way, quantitative and personalized assessment of the risk of developing CVD events can be put into practice. In addition, the predictive value of the physiological parameters and the advancing unobtrusive technologies are used for real-time, on-site detection of the physiological parameters, indicating the possibility for realtime risk prediction of the acute CVD events. Figure 8 depicts a blue print of real-time prediction of sudden cardiovascular events by physiological tests using unobtrusive technologies and wireless communication technologies [125, 133].

In the future, a personalized quantitative risk assessment and real-time prediction model for sudden CVD events can be further studied and verified by constructing animal models to mimic the cardiovascular disease progression of plaque rupture, thrombosis, and adverse events, before applying to persons. It is of great importance to develop unobtrusive monitoring techniques to provide more accurate and quantifiable prognostic information for screening of vulnerable patients before the events occur. The application of unobtrusive technologies may be widened for detecting other risk factors that reflect the process of arteriosclerosis, such as developing microfluid chips for biomarker analysis.

\section{Conflict of Interests}

The authors declare that there is no financial relationship with any product, service, or company mentioned in this paper.

\section{Acknowledgments}

This work is supported in part by the National Basic Research Program 973 (no. 2010CB732606), the Guangdong Innovation Research Team Fund for Low-Cost Healthcare Technologies in China, the External Cooperation Program of the Chinese Academy of Sciences (no. GJHZ1212), the Key Lab for Health Informatics of Chinese Academy of Sciences, and the National Natural Science Foundation of China (nos. 81101120 and 61002002).

\section{References}

[1] WHO, "Cardiovascular diseases (CVDs)," Tech. Rep., World Health Organization, Geneva, Switzerland, 2012.

[2] M. Naghavi, P. Libby, E. Falk et al., "From vulnerable plaque to vulnerable patient: a call for new definitions and risk assessment strategies: part II," Circulation, vol. 108, no. 15, pp. 1772-1778, 2003.

[3] J. Mackay, G. A. Mensah, S. Mendis, and K. Greenlund, "The atlas of heart disease and stroke," Tech. Rep., World Health Organization, Geneva, Switzerland, 2004.
[4] R. B. D’Agostino Sr., R. S. Vasan, M. J. Pencina et al., "General cardiovascular risk profile for use in primary care: the framingham heart study," Circulation, vol. 117, no. 6, pp. 743-753, 2008.

[5] S. M. Grundy, J. I. Cleeman, C. N. Merz et al., "Implications of recent clinical trials for the national cholesterol education program adult treatment panel III guidelines," Circulation, vol. 110, no. 2, pp. 227-239, 2004.

[6] R. M. Conroy, K. Pyörälä, A. P. Fitzgerald et al., "Estimation of ten-year risk of fatal cardiovascular disease in Europe: the SCORE project," European Heart Journal, vol. 24, no. 11, pp. 9871003, 2003.

[7] G. Assmann, P. Cullen, and H. Schulte, "Simple scoring scheme for calculating the risk of acute coronary events based on the 10-year follow-up of the prospective cardiovascular münster (PROCAM) study," Circulation, vol. 105, no. 3, pp. 310-315, 2002.

[8] J. Hippisley-Cox, C. Coupland, Y. Vinogradova, J. Robson, M. May, and P. Brindle, "Derivation and validation of QRISK, a new cardiovascular disease risk score for the United Kingdom: prospective open cohort study," British Medical Journal, vol. 335, no. 7611, pp. 136-141, 2007.

[9] P. M. Ridker, N. P. Paynter, N. Rifai, J. M. Gaziano, and N. R. Cook, "C-reactive protein and parental history improve global cardiovascular risk prediction: the reynolds risk score for men," Circulation, vol. 118, no. 22, pp. 2243-2251, 2008.

[10] P. M. Ridker, J. E. Buring, N. Rifai, and N. R. Cook, "Development and validation of improved algorithms for the assessment of global cardiovascular risk in women: the reynolds risk score," Journal of the American Medical Association, vol. 297, no. 6, pp. 611-619, 2007.

[11] Y. Wu, X. Liu, X. Li et al., "Estimation of 10-year risk of fatal and nonfatal ischemic cardiovascular diseases in Chinese adults," Circulation, vol. 114, no. 21, pp. 2217-2225, 2006.

[12] D. M. Lloyd-Jones, "Cardiovascular risk prediction: basic concepts, current status, and future directions," Circulation, vol. 121, no. 15 , pp. $1768-1777,2010$.

[13] S. C. Smith Jr., "Current and future directions of cardiovascular risk prediction," American Journal of Cardiology, vol. 97, 1, no. 2A, pp. 28A-32A, 2006.

[14] K. M. Johnson and D. A. Dowe, "The detection of any coronary calcium outperforms framingham risk score as a first step in screening for coronary atherosclerosis," American Journal of Roentgenology, vol. 194, no. 5, pp. 1235-1243, 2010.

[15] V. Fuster, F. Lois, and M. Franco, "Early identification of atherosclerotic disease by noninvasive imaging," Nature Reviews Cardiology, vol. 7, no. 6, pp. 327-333, 2010.

[16] L. N. Pu, Z. Zhao, and Y. T. Zhang, "Investigation on cardiovascular risk prediction using genetic information," IEEE Information Technology in Biomedicine, vol. 16, no. 5, pp. 795808, 2012.

[17] D. Tousoulis, G. Hatzis, N. Papageorgiou et al., "Assessment of acute coronary syndromes: focus on novel biomarkers," Current Medicinal Chemistry, vol. 19, no. 16, pp. 2572-2587, 2012.

[18] H. Lu, L. A. Cassis, and A. Daugherty, "Atherosclerosis and arterial blood pressure in mice," Current Drug Targets, vol. 8, no. 11, pp. 1181-1189, 2007.

[19] M. Naghavi, P. Libby, E. Falk et al., "From vulnerable plaque to vulnerable patient: a call for new definitions and risk assessment strategies: part I," Circulation, vol. 108, no. 14, pp. 1664-1672, 2003.

[20] P. Greenland, J. S. Alpert, G. A. Beller et al., "2010 ACCF/AHA guideline for assessment of cardiovascular risk in asymptomatic adults: a report of the American college of cardiology 
foundation/American heart association task force on practice guidelines," Circulation, vol. 122, no. 25, pp. e584-e636, 2010.

[21] G. Paolisso, M. R. Rizzo, M. Barbieri, D. Manzella, E. Ragno, and D. Maugeri, "Cardiovascular risk in type 2 diabetics and pharmacological regulation of mealtime glucose excursions," Diabetes and Metabolism, vol. 29, no. 4, part 1, pp. 335-340, 2003.

[22] G. Thrall, D. Lane, D. Carroll, and G. Y. H. Lip, "A systematic review of the prothrombotic effects of an acute change in posture: a possible mechanism underlying the morning excess in cardiovascular events?" Chest, vol. 132, no. 4, pp. 1337-1347, 2007.

[23] M. Kikuya, A. Hozawa, T. Ohokubo et al., "Prognostic significance of blood pressure and heart rate variabilities: the ohasama study," Hypertension, vol. 36, no. 5, pp. 901-906, 2000.

[24] E. Dolan, A. Stanton, L. Thijs et al., "Superiority of ambulatory over clinic blood pressure measurement in predicting mortality: the Dublin outcome study," Hypertension, vol. 46, no. 1, pp. 156161, 2005.

[25] G. D. Lewis, P. Gona, M. G. Larson et al., "Exercise blood pressure and the risk of incident cardiovascular disease (from the framingham heart study)," American Journal of Cardiology, vol. 101, no. 11, pp. 1614-1620, 2008.

[26] C. Vlachopoulos, K. Aznaouridis, and C. Stefanadis, "Prediction of cardiovascular events and all-cause mortality with arterial stiffness. a systematic review and meta-analysis," Journal of the American College of Cardiology, vol. 55, no. 13, pp. 13181327, 2010.

[27] H. E. Resnick, R. S. Lindsay, M. M. McDermott et al., "Relationship of high and low ankle brachial index to all-cause and cardiovascular disease mortality: the strong heart study," Circulation, vol. 109, no. 6, pp. 733-739, 2004.

[28] T. Giles, "Relevance of blood pressure variation in the circadian onset of cardiovascular events," Journal of Hypertension, vol. 23, no. 1, pp. S35-S39, 2005.

[29] M. S.-J. Rim, "Blood pressure variation and cardiovascular risks," Korean Circulation Journal, vol. 38, no. 3, pp. 131-134, 2008.

[30] A. Halkin, A. Steinvil, R. Rosso, A. Adler, U. Rozovski, and S. Viskin, "Preventing sudden death of athletes with electrocardiographic screening: what is the absolute benefit and how much will it cost?" Journal of the American College of Cardiology, vol. 60, no. 22, pp. 2271-2276, 2012.

[31] A. S. Gami, D. E. Howard, E. J. Olson, and V. K. Somers, "Daynight pattern of sudden death in obstructive sleep apnea," The New England Journal of Medicine, vol. 352, no. 12, pp. 1206-1279, 2005.

[32] M. A. Hlatky, P. Greenland, D. K. Arnett et al., "Criteria for evaluation of novel markers of cardiovascular risk: a scientific statement from the American heart association," Circulation, vol. 119, no. 17, pp. 2408-2416, 2009.

[33] K. Miura, H. Nakagawa, Y. Ohashi et al., "Four blood pressure indexes and the risk of stroke and myocardial infarction in Japanese men and women a meta-analysis of 16 cohort studies," Circulation, vol. 119, no. 14, pp. 1892-1898, 2009.

[34] P. M. Rothwell, S. C. Howard, E. Dolan et al., "Prognostic significance of visit-to-visit variability, maximum systolic blood pressure, and episodic hypertension," The Lancet, vol. 375, no. 9718, pp. 895-905, 2010.

[35] R. C. Hermida, D. E. Ayala, A. Mojón, and J. R. Fernández, "Decreasing sleep-time blood pressure determined by ambulatory monitoring reduces cardiovascular risk," Journal of the
American College of Cardiology, vol. 58, no. 11, pp. 1165-1173, 2011.

[36] G. Bilo, E. Dolan, E. O’Brien, and G. Parati, “Blood pressure variability as a predictor of cardiovascular mortality: results of Dublin outcome study: 4B. 01," Journal of Hypertension, vol. 28, article 209, 2010.

[37] S. A. Weiss, R. S. Blumenthal, A. R. Sharrett, R. F. Redberg, and S. Mora, "Exercise blood pressure and future cardiovascular death in asymptomatic individuals," Circulation, vol. 121, no. 19, pp. 2109-2116, 2010.

[38] S. Lewington, R. Clarke, N. Qizilbash, R. Peto, and R. Collins, "Age-specific relevance of usual blood pressure to vascular mortality: a meta-analysis of individual data for one million adults in 61 prospective studies," The Lancet, vol. 360, no. 9349, pp. 1903-1913, 2002.

[39] P. M. Rothwell, S. C. Howard, E. Dolan et al., "Effects of $\beta$ blockers and calcium-channel blockers on within-individual variability in blood pressure and risk of stroke," The Lancet Neurology, vol. 9, no. 5, pp. 469-480, 2010.

[40] P. M. Rothwell, "Limitations of the usual blood-pressure hypothesis and importance of variability, instability, and episodic hypertension," The Lancet, vol. 375, no. 9718, pp. 938948, 2010.

[41] A. J. Webb, U. Fischer, Z. Mehta, and P. M. Rothwell, "Effects of antihypertensive-drug class on interindividual variation in blood pressure and risk of stroke: a systematic review and metaanalysis," The Lancet, vol. 375, no. 9718, pp. 906-915, 2010.

[42] B. Carlberg and L. H. Lindholm, "Stroke and blood-pressure variation: new permutations on an old theme," The Lancet, vol. 375, no. 9718, pp. 867-869, 2010.

[43] H.-Q. Fan, Y. Li, L. Thijs et al., "Prognostic value of isolated nocturnal hypertension on ambulatory measurement in 8711 individuals from 10 populations," Journal of Hypertension, vol. 28, no. 10, pp. 2036-2045, 2010.

[44] T. W. Hansen, Y. Li, J. Boggia, L. Thijs, T. Richart, and J. A. Staessen, "Predictive role of the nighttime blood pressure," Hypertension, vol. 57, no. 1, pp. 3-10, 2011.

[45] P. Verdecchia, F. Angeli, and C. Cavallini, "Ambulatory blood pressure for cardiovascular risk stratification," Circulation, vol. 115, no. 16, pp. 2091-2093, 2007.

[46] J. Boggia, L. Thijs, T. W. Hansen et al., "Ambulatory blood pressure monitoring in 9357 subjects from 11 populations highlights missed opportunities for cardiovascular prevention in women," Hypertension, vol. 57, no. 3, pp. 397-405, 2011.

[47] T. W. Hansen, L. Thijs, Y. Li et al., "Prognostic value of readingto-reading blood pressure variability over 24 hours in 8938 subjects from 11 populations," Hypertension, vol. 55, no. 4, pp. 1049-1057, 2010.

[48] G. Mancia, M. Bombelli, R. Facchetti et al., "Long-term prognostic value of blood pressure variability in the general population: results of the pressioni arteriose monitorate $\mathrm{e}$ lassociazioni study," Hypertension, vol. 49, no. 6, pp. 1265-1270, 2007.

[49] E. Ingelsson, K. Björklund-Bodegård, L. Lind, J. Ärnlöv, and J. Sundström, "Diurnal blood pressure pattern and risk of congestive heart failure," Journal of the American Medical Association, vol. 295, no. 24, pp. 2859-2866, 2006.

[50] J. Zeng, M. Jia, H. Ran et al., "Fixed-combination of amlodipine and diuretic chronotherapy in the treatment of essential hypertension: improved blood pressure control with bedtime dosinga multicenter, open-label randomized study," Hypertension Research, vol. 34, no. 6, pp. 767-772, 2011. 
[51] N. Miyai, M. Arita, I. Morioka, S. Takeda, and K. Miyashita, "Ambulatory blood pressure, sympathetic activity, and left ventricular structure and function in middle-aged normotensive men with exaggerated blood pressure response to exercise," Medical Science Monitor, vol. 11, no. 10, pp. CR478-CR484, 2005.

[52] P. S. Ramos and C. G. S. Araújo, "Normotensive individuals with exaggerated exercise blood pressure response have increased cardiac vagal tone," Arquivos Brasileiros de Cardiologia, vol. 95, no. 1, pp. 85-90, 2010.

[53] N. Kucukler, F. Yalçin, T. P. Abraham, and M. J. Garcia, "Stress induced hypertensive response: should it be evaluated more carefully?" Cardiovascular Ultrasound, vol. 9, no. 1, article 22, 2011.

[54] K. Ellis, C. E. Pothier, E. H. Blackstone, and M. S. Lauer, "Is systolic blood pressure recovery after exercise a predictor of mortality?" American Heart Journal, vol. 147, no. 2, pp. 287-292, 2004.

[55] E. A. Ashley, V. Raxwal, and V. Froelicher, "An evidence-based review of the resting electrocardiogram as a screening technique for heart disease," Progress in Cardiovascular Diseases, vol. 44, no. 1, pp. 55-67, 2001.

[56] Z. M. Zhang, R. J. Prineas, and C. B. Eaton, "Evaluation and comparison of the minnesota code and novacode for electrocardiographic Q-ST wave abnormalities for the independent prediction of Incident coronary heart disease and total mortality (from the women's health initiative)," American Journal of Cardiology, vol. 106, no. 1, pp. 18-25, 2010.

[57] M. A. Bauml and D. A. Underwood, "Left ventricular hypertrophy: an overlooked cardiovascular risk factor," Cleveland Clinic Journal of Medicine, vol. 77, no. 6, pp. 381-387, 2010.

[58] N. Rumana, T. C. Turin, K. Miura et al., "Prognostic value of ST$\mathrm{T}$ abnormalities and left high $\mathrm{R}$ waves with cardiovascular mortality in Japanese (24-Year follow-up of NIPPON DATA80)," American Journal of Cardiology, vol. 107, no. 12, pp. 1718-1724, 2011.

[59] L. Oikarinen, M. S. Nieminen, M. Viitasalo et al., "QRS duration and QT interval predict mortality in hypertensive patients with left ventricular hypertrophy: the losartan intervention for endpoint reduction in hypertension study," Hypertension, vol. 43, no. 5, pp. 1029-1034, 2004.

[60] G. F. Salles, W. Deccache, and C. R. L. Cardoso, "Usefulness of QT-interval parameters for cardiovascular risk stratification in type 2 diabetic patients with arterial hypertension," Journal of Human Hypertension, vol. 19, no. 3, pp. 241-249, 2005.

[61] P. Denes, J. C. Larson, D. M. Lloyd-Jones, R. J. Prineas, and P. Greenland, "Major and minor ECG abnormalities in asymptomatic women and risk of cardiovascular events and mortality," Journal of the American Medical Association, vol. 297, no. 9, pp. 978-985, 2007.

[62] C. T. Larsen, J. Dahlin, H. Blackburn et al., "Prevalence and prognosis of electrocardiographic left ventricular hypertrophy, ST segment depression and negative T-wave: the Copenhagen city heart study," European Heart Journal, vol. 23, no. 4, pp. 315324, 2002.

[63] P. M. Okin, R. B. Devereux, M. S. Nieminen et al., "Electrocardiographic strain pattern and prediction of cardiovascular morbidity and mortality in hypertensive patients," Hypertension, vol. 44, no. 1, pp. 48-54, 2004.

[64] D. De Bacquer, G. De Backer, M. Kornitzer, K. Myny, Z. Doyen, and H. Blackburn, "Prognostic value of ischemic electrocardiographic findings for cardiovascular mortality in men and women," Journal of the American College of Cardiology, vol. 32, no. 3, pp. 680-685, 1998.

[65] S. Bangalore, F. H. Messerli, F. S. Ou et al., "The association of admission heart rate and in-hospital cardiovascular events in patients with non-ST-segment elevation acute coronary syndromes: results from 135164 patients in the CRUSADE quality improvement initiative," European Heart Journal, vol. 31, no. 5, pp. 552-560, 2010.

[66] R. Kolloch, U. F. Legler, A. Champion et al., "Impact of resting heart rate on outcomes in hypertensive patients with coronary artery disease: findings from the INternational VErapamil-SR/ trandolapril STudy (INVEST)," European Heart Journal, vol. 29, no. 10, pp. 1327-1334, 2008.

[67] M. T. Cooney, E. Vartiainen, T. Laakitainen, A. Juolevi, A. Dudina, and I. M. Graham, "Elevated resting heart rate is an independent risk factor for cardiovascular disease in healthy men and women," American Heart Journal, vol. 159, no. 4, pp. 612-619, 2010.

[68] G. Parodi, B. Bellandi, R. Valenti et al., "Heart rate as an independent prognostic risk factor in patients with acute myocardial infarction undergoing primary percutaneous coronary intervention," Atherosclerosis, vol. 211, no. 1, pp. 255-259, 2010.

[69] K. Fox, J. S. Borer, A. J. Camm et al., "Resting heart rate in cardiovascular disease," Journal of the American College of Cardiology, vol. 50, no. 9, pp. 823-830, 2007.

[70] J. S. Borer, “Heart rate: from risk marker to risk factor," European Heart Journal supplements, vol. 10, pp. F2-F6, 2008.

[71] K. Fox, R. Ferrari, M. Tendera, P. G. Steg, and I. Ford, "Rationale and design of a randomized, double-blind, placebo-controlled trial of ivabradine in patients with stable coronary artery disease and left ventricular systolic dysfunction: the morBiditymortality EvAlUaTion of the If inhibitor ivabradine in patients with coronary disease and left ventricULar dysfunction (BEAUTIFUL) Study," American Heart Journal, vol. 152, no. 5, pp. 860866, 2006.

[72] U. E. Heidland and B. E. Strauer, "Left ventricular muscle mass and elevated heart rate are associated with coronary plaque disruption," Circulation, vol. 104, no. 13, pp. 1477-1482, 2001.

[73] T. W. Hansen, L. Thijs, J. Boggia et al., "Prognostic value of ambulatory heart rate revisited in 6928 subjects from 6 populations," Hypertension, vol. 52, no. 2, pp. 229-235, 2008.

[74] P. M. Okin, R. B. Devereux, S. Jern et al., "Regression of electrocardiographic left ventricular hypertrophy during antihypertensive treatment and the prediction of major cardiovascular events," Journal of the American Medical Association, vol. 292, no. 19, pp. 2343-2349, 2004.

[75] A. Oberman, R. J. Prineas, J. C. Larson, A. LaCroix, and N. L. Lasser, "Prevalence and determinants of electrocardiographic left ventricular hypertrophy among a multiethnic population of postmenopausal women (The Women's Health Initiative)," American Journal of Cardiology, vol. 97, no. 4, pp. 512-519, 2006.

[76] A. Jain, H. Tandri, D. Dalal et al., "Diagnostic and prognostic utility of electrocardiography for left ventricular hypertrophy defined by magnetic resonance imaging in relationship to ethnicity: the Multi-Ethnic Study of Atherosclerosis (MESA)," American Heart Journal, vol. 159, no. 4, pp. 652-658, 2010.

[77] A. Kumar, R. J. Prineas, A. M. Arnold et al., "Prevalence, prognosis, and implications of isolated minor nonspecific STsegment and T-wave abnormalities in older adults cardiovascular health study," Circulation, vol. 118, no. 25, pp. 2790-2796, 2008 . 
[78] E. Z. Soliman, R. J. Prineas, L. D. Case et al., "Electrocardiographic and clinical predictors separating atherosclerotic sudden cardiac death from incident coronary heart disease," Heart, vol. 97, no. 19, pp. 1597-1601, 2011.

[79] M. J. G. Leening, S. E. Elias-Smale, J. F. Felix et al., "Unrecognised myocardial infarction and long-term risk of heart failure in the elderly: the Rotterdam study," Heart, vol. 96, no. 18, pp. 1458-1462, 2010.

[80] E. Sigurdsson, G. Thorgeirsson, H. Sigvaldason, and N. Sigfusson, "Unrecognized myocardial infarction: epidemiology, clinical characteristics, and the prognostic role of angina pectoris. the Reykjavik study," Annals of Internal Medicine, vol. 122, no. 2, pp. 96-102, 1995.

[81] A. Bauer, J. W. Kantelhardt, P. Barthel et al., "Deceleration capacity of heart rate as a predictor of mortality after myocardial infarction: cohort study," The Lancet, vol. 367, no. 9523, pp. 16741681, 2006.

[82] G. Kudaiberdieva, B. Görenek, and B. Timuralp, "Heart rate variability as a predictor of sudden cardiac death," Anadolu Kardiyoloji Dergisi, vol. 7, no. 1, pp. 68-70, 2007.

[83] E. Z. Gorodeski, H. Ishwaran, E. H. Blackstone, and M. S. Lauer, "Quantitative electrocardiographic measures and longterm mortality in exercise test patients with clinically normal resting electrocardiograms," American Heart Journal, vol. 158, no. 1, pp. 61-70, 2009.

[84] S. Mora, R. F. Redberg, Y. Cui et al., "Ability of exercise testing to predict cardiovascular and all-Cause death in asymptomatic women: a 20-Year follow-up of the lipid research clinics prevalence study," Journal of the American Medical Association, vol. 290, no. 12, pp. 1600-1607, 2003.

[85] Y. Nishiyama, H. Morita, H. Harada et al., "Systolic blood pressure response to exercise as a predictor of mortality in patients with chronic heart failure," International Heart Journal, vol. 51, no. 2, pp. 111-115, 2010.

[86] C. W. Israel, "Non-invasive risk stratification: prognostic implications of exercise testing," Herzschrittmachertherapie und Elektrophysiologie, vol. 18, no. 1, pp. 17-29, 2007.

[87] J. A. Laukkanen, T. H. Mäkikallio, R. Rauramaa, and S. Kurl, "Asymptomatic ST-segment depression during exercise testing and the risk of sudden cardiac death in middle-aged men: a population-based follow-up study," European Heart Journal, vol. 30, no. 5, pp. 558-565, 2009.

[88] X. Jouven, J. P. Empana, P. J. Schwartz, M. Desnos, D. Courbon, and P. Ducimetière, "Heart-rate profile during exercise as a predictor of sudden death," The New England Journal of Medicine, vol. 352, no. 19, pp. 1951-1958, 2005.

[89] M. S. Lauer, C. E. Pothier, D. J. Magid, S. S. Smith, and M. W. Kattan, "An externally validated model for predicting longterm survival after exercise treadmill testing in patients with suspected coronary artery disease and a normal electrocardiogram," Annals of Internal Medicine, vol. 147, no. 12, pp. 821-828, 2007.

[90] J. Myers, S. Y. Tan, J. Abella, V. Aleti, and V. F. Froelicher, "Comparison of the chronotropic response to exercise and heart rate recovery in predicting cardiovascular mortality," European Journal of Cardiovascular Prevention and Rehabilitation, vol. 14, no. 2, pp. 215-221, 2007.

[91] T. D. Miller, "The exercise treadmill test: estimating cardiovascular prognosis," Cleveland Clinic Journal of Medicine, vol. 75, no. 6, pp. 424-430, 2008.

[92] A. S. Adabag, G. A. Grandits, R. J. Prineas, R. S. Crow, H. E. Bloomfield, and J. D. Neaton, "Relation of heart rate parameters during exercise test to sudden death and all-cause mortality in asymptomatic men," American Journal of Cardiology, vol. 101, no. 10, pp. 1437-1443, 2008.

[93] E. O. Nishime, C. R. Cole, E. H. Blackstone, F. J. Pashkow, and M. S. Lauer, "Heart rate recovery and treadmill exercise score as predictors of mortality in patients referred for exercise ECG," Journal of the American Medical Association, vol. 284, no. 11, pp. $1392-1398,2000$.

[94] M. E. Safar, J. Blacher, and P. Jankowski, "Arterial stiffness, pulse pressure, and cardiovascular disease-Is it possible to break the vicious circle?" Atherosclerosis, vol. 218, no. 2, pp. 263-271, 2011.

[95] S. S. Franklin, "Beyond blood pressure: arterial stiffness as a new biomarker of cardiovascular disease," Journal of the American Society of Hypertension, vol. 2, no. 3, pp. 140-151, 2008.

[96] H. Tanaka, M. Munakata, Y. Kawano et al., "Comparison between carotid-femoral and brachial-ankle pulse wave velocity as measures of arterial stiffness," Journal of Hypertension, vol. 27, no. 10, pp. 2022-2027, 2009.

[97] C. Giannattasio, "Aortic stiffness as a predictor of coronary atherosclerosis," Journal of Hypertension, vol. 24, no. 12, pp. 2347-2348, 2006.

[98] S. Laurent, J. Cockcroft, L. Van Bortel et al., "Expert consensus document on arterial stiffness: methodological issues and clinical applications," European Heart Journal, vol. 27, no. 21, pp. 2588-2605, 2006.

[99] G. F. Mitchell, S. J. Hwang, R. S. Vasan et al., "Arterial stiffness and cardiovascular events: the framingham heart study," Circulation, vol. 121, no. 4, pp. 505-511, 2010.

[100] F. U. Mattace-Raso, T. J. Van Der Cammen, A. Hofman et al., "Arterial stiffness and risk of coronary heart disease and stroke: the Rotterdam Study," Circulation, vol. 113, no. 5, pp. 657-663, 2006.

[101] R. Pini, M. C. Cavallini, V. Palmieri et al., "Central but not brachial blood pressure predicts cardiovascular events in an unselected geriatric population. the ICARe Dicomano Study," Journal of the American College of Cardiology, vol. 51, no. 25, pp. 2432-2439, 2008.

[102] M. J. Roman, R. B. Devereux, J. R. Kizer et al., "Central pressure more strongly relates to vascular disease and outcome than does brachial pressure: the strong heart study," Hypertension, vol. 50, no. 1, pp. 197-203, 2007.

[103] H. Miyashita, A. Aizawa, J. Hashimoto et al., "Cross-sectional characterization of all classes of antihypertensives in terms of central blood pressure in Japanese hypertensive patients," American Journal of Hypertension, vol. 23, no. 3, pp. 260-268, 2010.

[104] J. A. Chirinos, J. P. Zambrano, S. Chakko et al., "Aortic pressure augmentation predicts adverse cardiovascular events in patients with established coronary artery disease," Hypertension, vol. 45, no. 5, pp. 980-985, 2005.

[105] T. Weber, J. Auer, M. F. O’Rourke et al., "Arterial stiffness, wave reflections, and the risk of coronary artery disease," Circulation, vol. 109, no. 2, pp. 184-189, 2004.

[106] G. M. London, J. Blacher, B. Pannier, A. P. Guérin, S. J. Marchais, and M. E. Safar, "Arterial wave reflections and survival in endstage renal failure," Hypertension, vol. 38, no. 3, pp. 434-438, 2001.

[107] T. Weber, J. Auer, G. Lamm, M. F. O’Rourke, and B. Eber, "Arterial stiffness, central blood pressures, and wave reflections in cardiomyopathy-Implications for risk stratification," Journal of Cardiac Failure, vol. 13, no. 5, pp. 353-359, 2007. 
[108] P. S. Lacy, D. G. O’Brien, A. G. Stanley, M. M. Dewar, P. P. R. Swales, and B. Williams, "Increased pulse wave velocity is not associated with elevated augmentation index in patients with diabetes," Journal of Hypertension, vol. 22, no. 10, pp. 1937-1944, 2004.

[109] K. L. Wang, H. M. Cheng, S. H. Sung et al., "Wave reflection and arterial stiffness in the prediction of 15-year all-cause and cardiovascular mortalities: a community-based study," Hypertension, vol. 55, no. 3, pp. 799-805, 2010.

[110] E. Dolan, L. Thijs, Y. Li et al., "Ambulatory arterial stiffness index as a predictor of cardiovascular mortality in the Dublin outcome study," Hypertension, vol. 47, no. 3, pp. 365-370, 2006.

[111] C. M. McEniery, Y. Yasmin, I. R. Hall, A. Qasem, I. B. Wilkinson, and J. R. Cockcroft, "Normal vascular aging: differential effects on wave reflection and aortic pulse wave velocity: the AngloCardiff Collaborative Trial (ACCT)," Journal of the American College of Cardiology, vol. 46, no. 9, pp. 1753-1760, 2005.

[112] F. G. Fowkes, M. Criqui, and G. D. Murray, "Ankle brachial index improves prediction of mortality determined by Framingham risk score in 48, 115 healthy subjects in sixteen studies worldwide," Circulation, vol. 114, article II_907, 2006.

[113] F. G. Fowkes, G. D. Murray, I. Butcher et al., "Ankle brachial index combined with framingham risk score to predict cardiovascular events and mortality: a meta-analysis," Journal of the American Medical Association, vol. 300, no. 2, pp. 197-208, 2008.

[114] J. Yeboah, R. L. McClelland, T. S. Polonsky et al., "Comparison of novel risk markers for improvement in cardiovascular risk assessment in intermediate-risk individuals," The Journal of the American Medical Association, vol. 308, no. 8, pp. 788-795, 2012.

[115] J. B. Meigs, D. M. Nathan, R. B. D’Agostino Sr., and P. W. F. Wilson, "Fasting and postchallenge glycemia and cardiovascular disease risk: the framingham offspring study," Diabetes Care, vol. 25, no. 10, pp. 1845-1850, 2002.

[116] American Diabetes Association, "Diagnosis and classification of diabetes mellitus," Diabetes Care, vol. 35, pp. 562-569, 2012.

[117] N. Sarwar, P. Gao, S. R. Seshasai et al., "Fasting blood glucose concentration, and risk of vascular disease: a collaborative meta-analysis of 102 prospective studies," The Lancet, vol. 375, no. 9733, pp. 2215-2222, 2010.

[118] Q. Qiao, K. Pyörälä, M. Pyörälä et al., "Two-hour glucose is a better risk predictor for incident coronary heart disease and cardiovascular mortality than fasting glucose," European Heart Journal, vol. 23, no. 16, pp. 1267-1275, 2002.

[119] K. A. Eagle, G. S. Ginsburg, K. Musunuru et al., "Identifying patients at high risk of a cardiovascular event in the near future: current status and future directions: report of a national heart, lung, and blood institute working group," Circulation, vol. 121, no. 12, pp. 1447-1454, 2010.

[120] T. A. Manolio, R. A. Kronmal, G. L. Burke, D. H. O’Leary, and T. R. Price, "Short-term predictors of incident stroke in older adults: the cardiovascular health study," Stroke, vol. 27, no. 9, pp. 1479-1486, 1996.

[121] S. Lange, H. J. Trampisch, R. Haberl et al., "Excess 1-year cardiovascular risk in elderly primary care patients with a low ankle-brachial index (ABI) and high homocysteine level," Atherosclerosis, vol. 178, no. 2, pp. 351-357, 2005.

[122] T. Weber, J. Auer, M. F. O’Rourke et al., "Increased arterial wave reflections predict severe cardiovascular events in patients undergoing percutaneous coronary interventions," European Heart Journal, vol. 26, no. 24, pp. 2657-2663, 2005.

[123] M. R. Nelson, J. Stepanek, M. Cevette, M. Covalciuc, R. T. Hurst, and A. J. Tajik, "Noninvasive measurement of central vascular pressures with arterial tonometry: clinical revival of the pulse pressure waveform?" Mayo Clinic Proceedings, vol. 85, no. 5, pp. 460-472, 2010.

[124] A. Dogui, N. Kachenoura, F. Frouin et al., "Consistency of aortic distensibility and pulse wave velocity estimates with respect to the Bramwell-Hill theoretical model: a cardiovascular magnetic resonance study," Journal of Cardiovascular Magnetic Resonance, vol. 13, article 11, 2011.

[125] C. C. Y. Poon, Q. Liu, H. Gao, W. H. Lin, and Y. T. Zhang, "Wearable intelligent systems for E-health," Journal of Computing Science and Engineering, vol. 5, no. 3, pp. 246-256, 2011.

[126] M. Z. Poh, D. J. McDuff, and R. W. Picard, "Non-contact, automated cardiac pulse measurements using video imaging and blind source separation," Optics Express, vol. 18, no. 10, pp. 10762-10774, 2010.

[127] S. Suzuki, T. Matsui, H. Imuta et al., "A novel autonomic activation measurement method for stress monitoring: noncontact measurement of heart rate variability using a compact microwave radar," Medical and Biological Engineering and Computing, vol. 46, no. 7, pp. 709-714, 2008.

[128] K. G. Ng, C. M. Ting, J. H. Yeo et al., "Progress on the development of the MediWatch ambulatory blood pressure monitor and related devices," Blood Pressure Monitoring, vol. 9, no. 3, pp. 149-165, 2004.

[129] C. C. Y. Poon, Y. M. Wong, and Y. T. Zhang, "M-health: the development of cuff-less and wearable blood pressure meters for use in body sensor networks," in Proceedings of the IEEE/NLM Life Science Systems and Applications Workshop (LSSA '06), Bethesda, Md, USA, July 2006.

[130] P. Shaltis, A. Reisner, and H. Asada, "Calibration of the photoplethysmogram to arterial blood pressure: capabilities and limitations for continuous pressure monitoring," in Proceedings of the 27th Annual International Conference of the Engineering in Medicine and Biology Society (IEEE-EMBS '05), pp. 3970-3973, Shanghai, China, September 2005.

[131] C. M. Girardin, C. Huot, M. Gonthier, and E. Delvin, "Continuous glucose monitoring: a review of biochemical perspectives and clinical use in type 1 diabetes," Clinical Biochemistry, vol. 42, no. 3, pp. 136-142, 2009.

[132] C. E. Ferrante do Amaral and B. Wolf, "Current development in non-invasive glucose monitoring," Medical Engineering and Physics, vol. 30, no. 5, pp. 541-549, 2008.

[133] M. J. Tierney, J. A. Tamada, R. O. Potts, L. Jovanovic, and S. Garg, "Clinical evaluation of the GlucoWatch biographer: a continual, non-invasive glucose monitor for patients with diabetes," Biosensors and Bioelectronics, vol. 16, no. 9-12, pp. 621-629, 2001.

[134] Y. Liu, C. C. Poon, Y. T. Zhang, G. W. Yip, and C. M. Yu, "A novel method for assessing arterial stiffness by a hydrostatic approach," in Proceedings of the Annual International Conference of the IEEE Engineering in Medicine and Biology Society (EMBC '09), pp. 1789-1791, Engineering in Medicine and Biology Society, Minneapolis, Minn, USA, 2009.

[135] Y. T. Zhang, C. C. Y. Poon, C. H. Chan, M. W. W. Tsang, and $\mathrm{K} . \mathrm{F}$. Wu, "A health-shirt using e-textile materials for the continuous and cuffless monitoring of arterial blood pressure," in Proceedings of the 3rd IEEE-EMBS International Summer School and Symposium on Medical Devices and Biosensors (ISSSMDBS '06), pp. 86-89, Boston, Mass, USA, September 2006.

[136] A. Beard, M. L. Neal, N. Tabesh-Saleki et al., "Multiscale modeling and data integration in the virtual physiological rat 
project," Annals of Biomedical Engineering, vol. 40, no. 11, pp. 2365-2378, 2012.

[137] P. J. Hunter and T. K. Borg, "Integration from proteins to organs: the physiome project," Nature Reviews Molecular Cell Biology, vol. 4, no. 3, pp. 237-243, 2003.

[138] "Wellcome trust heart physiome project," 2004, http://heart .physiomeproject.org/index.html.

[139] N. Smith, A. D. de Vecchi, M. McCormick et al., "euHeart: personalized and integrated cardiac care using patient-specific cardiovascular modelling," Interface Focus, vol. 1, no. 3, pp. 349364, 2011.

[140] V. Y. Wang, H. I. Lam, D. B. Ennis, B. R. Cowan, A. A. Young, and M. P. Nash, "Modelling passive diastolic mechanics with quantitative MRI of cardiac structure and function," Medical Image Analysis, vol. 13, no. 5, pp. 773-784, 2009.

[141] P. Hunter, N. Smith, J. Fernandez, and M. Tawhai, "Integration from proteins to organs: the IUPS physiome project," Mechanisms of Ageing and Development, vol. 126, no. 1, pp. 187-192, 2005. 


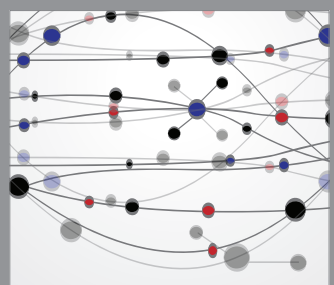

The Scientific World Journal
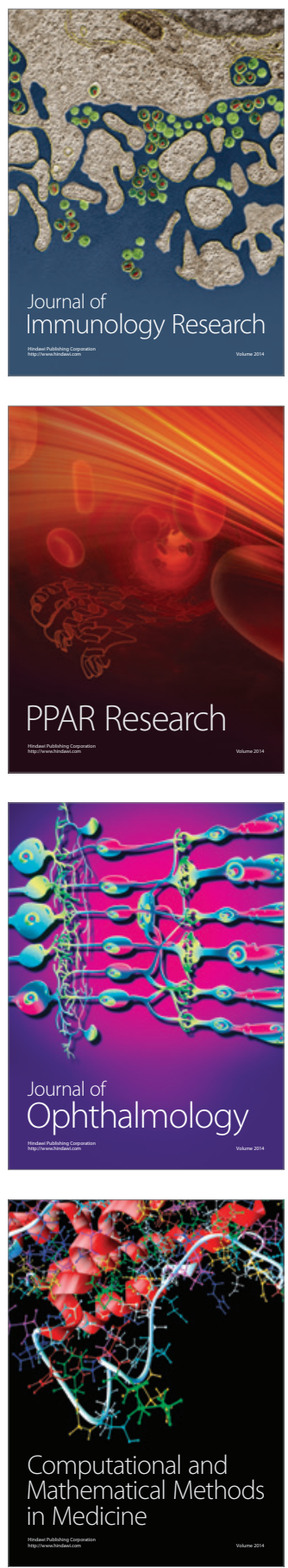

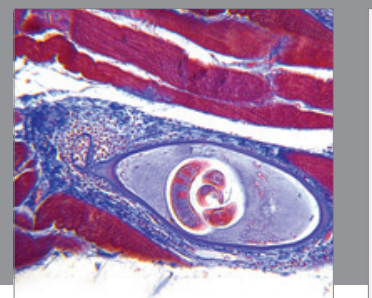

Gastroenterology

Research and Practice
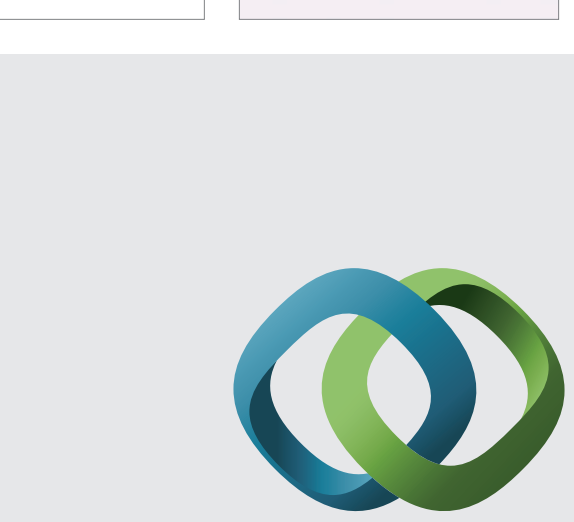

\section{Hindawi}

Submit your manuscripts at

http://www.hindawi.com
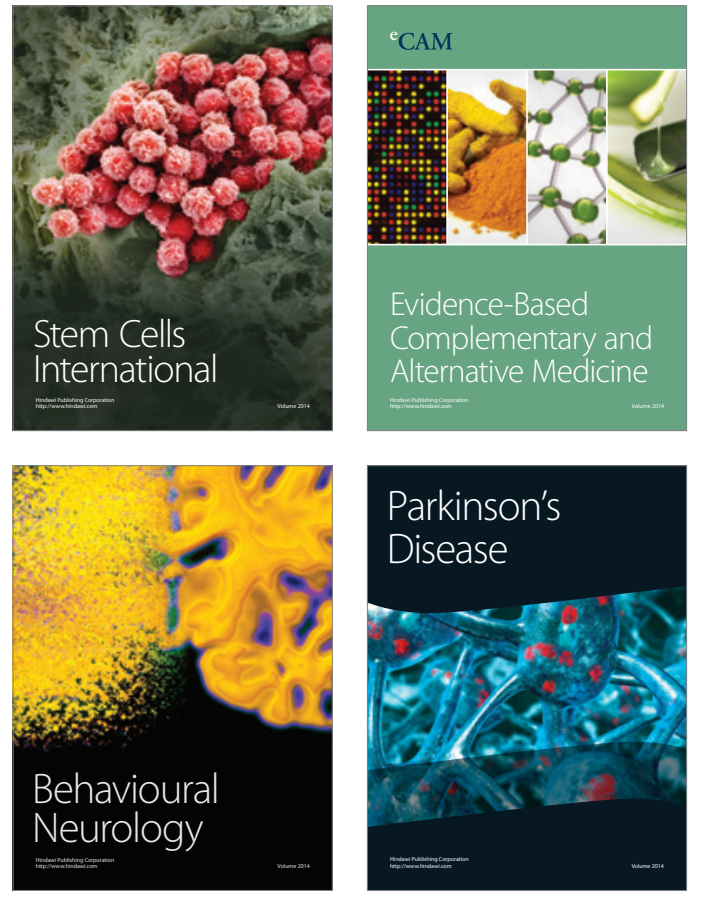
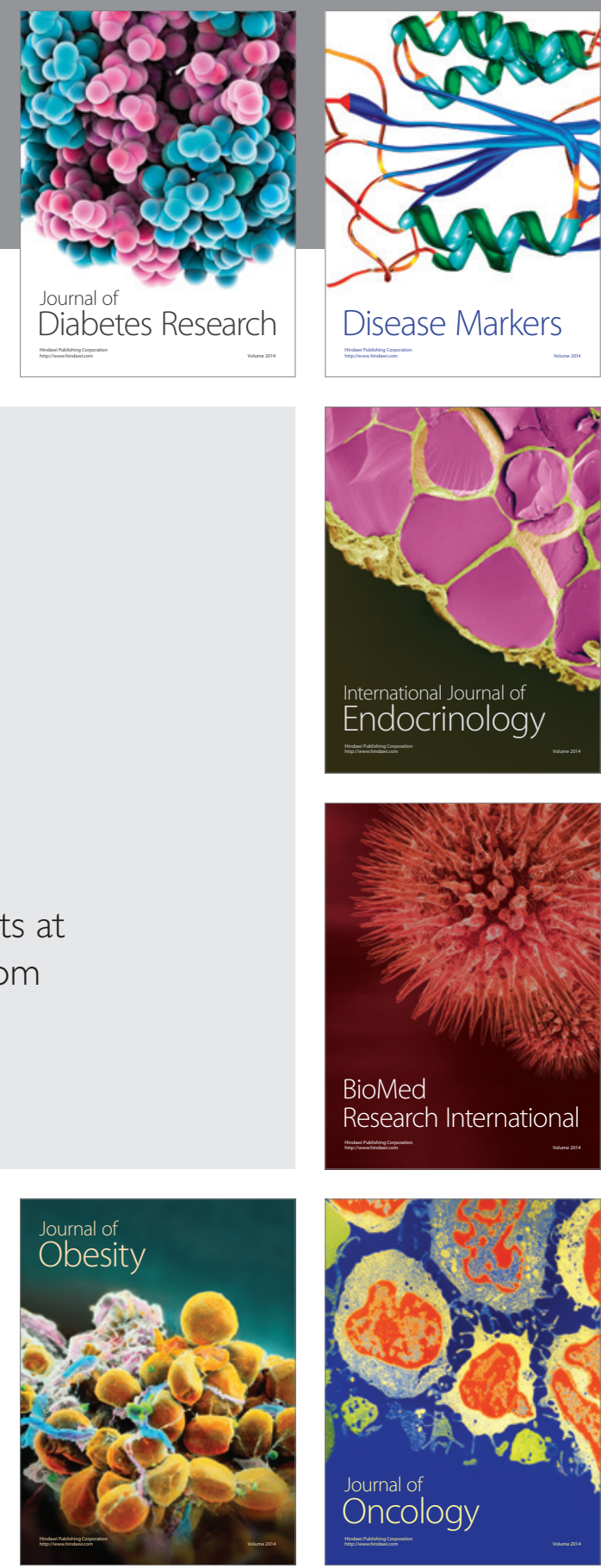

Disease Markers
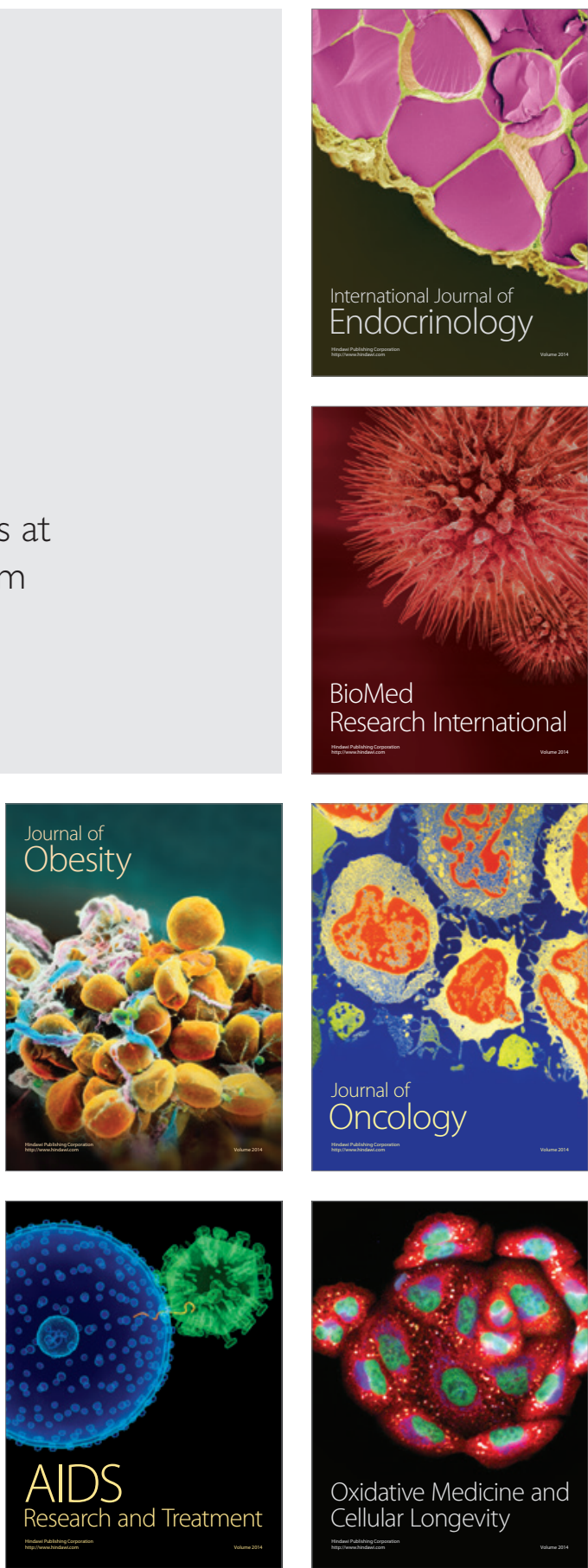